المجلة الدولية للدراسات التربوية والنفسية

International Journal of Educational \& Psychological Studies (EPS)

Journal Homepage: https://www.refaad.com/views/EPSR/Home.aspx

www.refaad.com

ISSN: 2520-4149 (Online) 2520-4130 (Print)

فعالية وحدة تعليمية مقترحة في إكساب بعض المهارات الحاسوبية الأساسية لطفل ما قبل المدرسة

\author{
ميمونة بنت محمد مكي بن هداية الله عبدالتواب

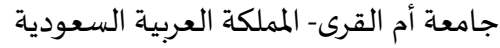 \\ maabdultawab@uqu.edu.sa
}

DOI: https://doi.org/DOI:10.31559/EPS2020.8.2.4

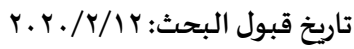

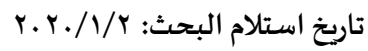

الملتخص:

تهدف الدراسـة الحالية إلى معرفة فعالية وحدة تعليمية مقترحة في إكساب بعض المهارات الحاسوبية الأساسية لطفل ما قبل المدرسـة، واتبعت الباحثة المنهج شباء التجريبي القائم على تصميم مجموعتين إحداهما تمثل المجموعة الضابطة، والأخرى تمثل المجموعة التجريبية ذات الاختبار القبلي

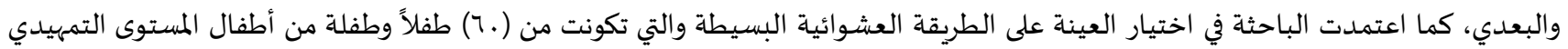
بروضة شعاع المعرفة بالعاصمة المقدسة، حيث قسمت عينة الدراسة إلى مجموعتين مجموعة تجريبية بلغ عددها (.r) طفلاً وطفلة، ومجموعة

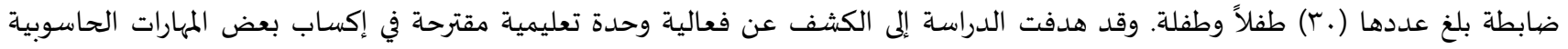
الأساسية في المجال المعرفي والأدائي لطفل ما قبل المدرسة، والكشف عما وإذا وإ كان هناك فروق بين الذكور والإناث من أفراد المجموعة التجريبية في

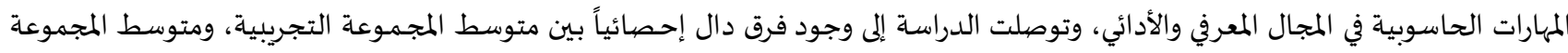

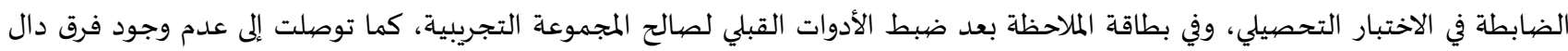

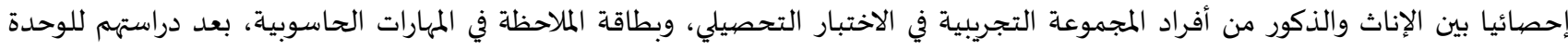

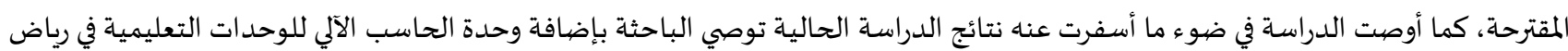

الأطفال، وتقديم الوحدات التعليمية في رياض الأطفال على الأقراص المضغوطة تماشياً مع استراتيجية التعليم الإلكتروني، والمراحل التعليمية.

الكلمات المفتاحية: مهارات؛ حاسوبية؛ طفل؛ قبل المدرسة؛ وحدة تعليمية.

\title{
(ㄷ) (b)
}

المقدمة:

تعتبر مرحلة رياض الأطفال في كلّ الدّول المتقدّمة مرحلةً تربويّة تعليميّة هادفة، لارتباطها بمرحلة الطّفولة المبكرة التي تعتبر من أخصب وأخطر

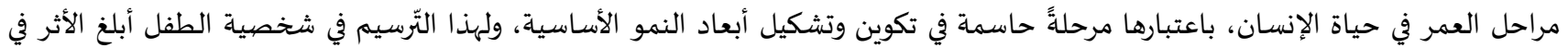

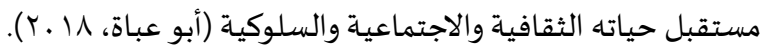

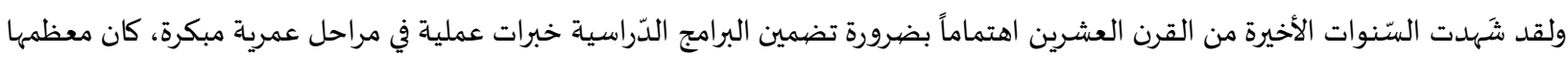
مرتبطا بالحاسب الآلي وتطبيقاته في التّعلم والتعليم(سليمان والجمال، Y . . r، 11) لذلك كان من المنطقي مواجهة هذه الثّقافة البديلة، وتهيئة

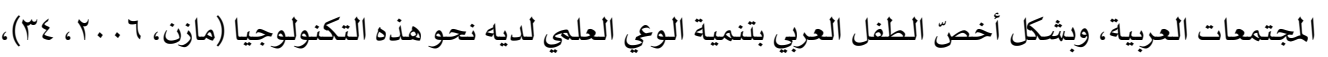
ويعد الحاسب الآلي من أهمّ المنتجات والتطبيقات لتكنولوجيا المعلومات والاتصالات، ويقوم الآباء بتزويد أطفالهم في المنزل بالخبرة الخاصية

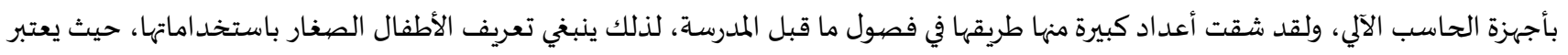
تعلم الحاسب الآلي أحد الأولويات بالنسبة للصغار باعتباره أداة المستقبل، ويمثل شكلاً من أشكال التكنولوجيا التي لها تأثيرٌ عميق بالفعل على بلى

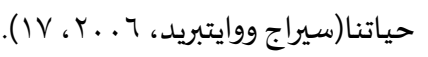
حيث إن الخبراء يؤكدون أنّ الطفل في سن العامين، أو ثلاثة الأعوام يمكنه استخدام الحاسب الآلي وفي سن الرابعة يبحر في عالم الإنترنت، حيث

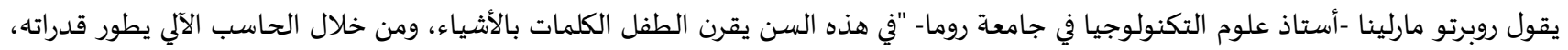

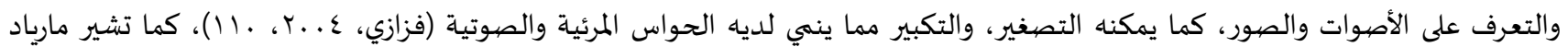


إلى أنّ الأطفال من rا: ع سنوات تتطور المهارات الحركية الدّقيقة لديهم بسرعة من خلال اللعب بأنشطة الحاسب الآلي (MARYAD, 2005,57)

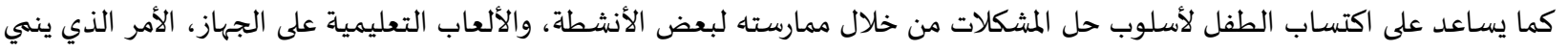

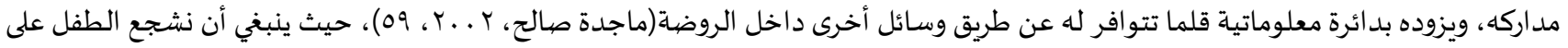

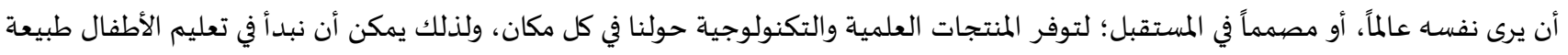

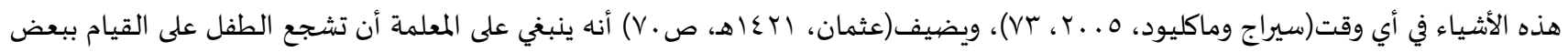

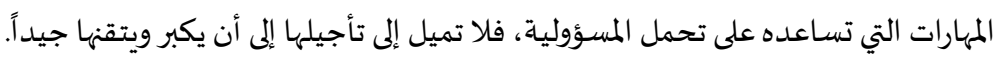

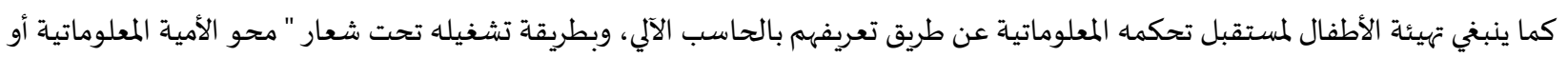

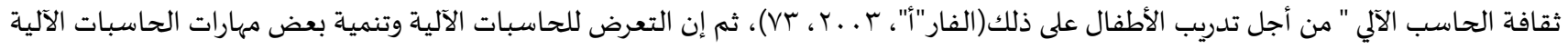

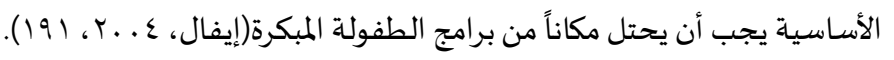

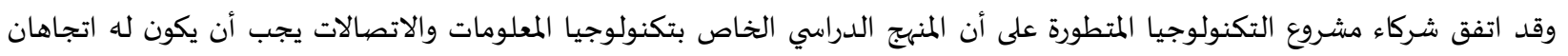

منفصصلان:

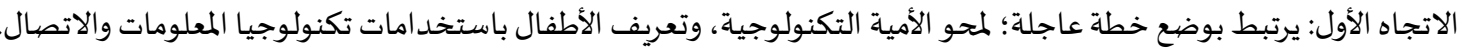

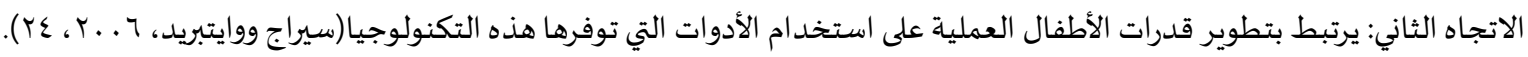

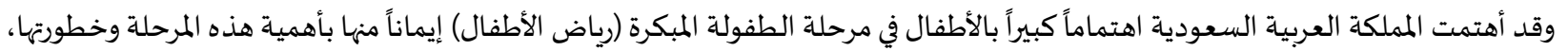

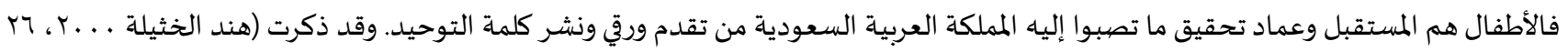

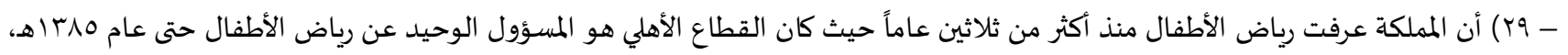

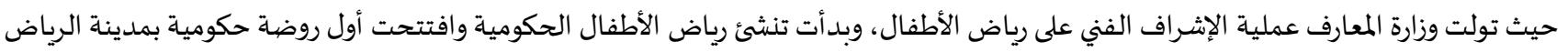

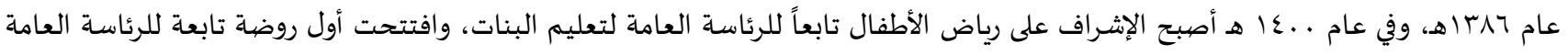

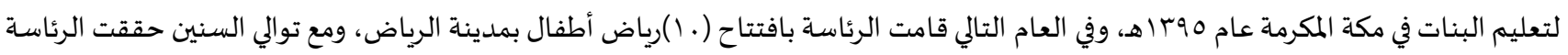

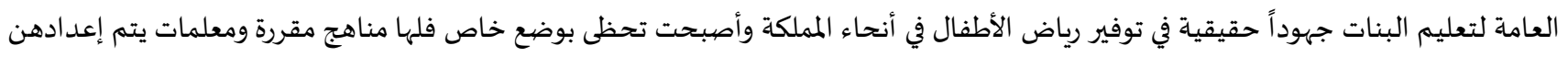

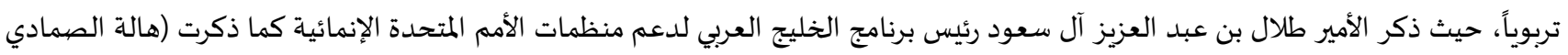

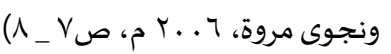

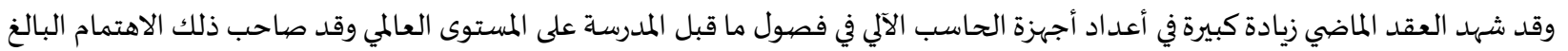

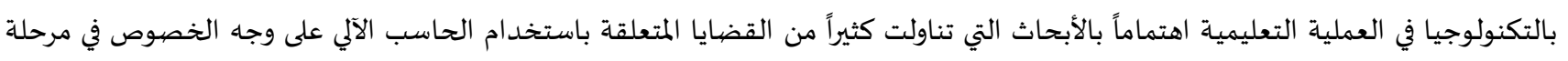

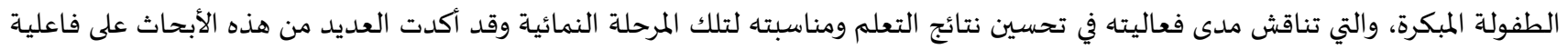

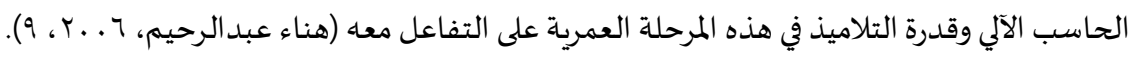

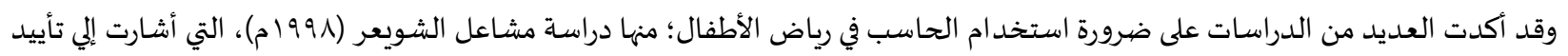

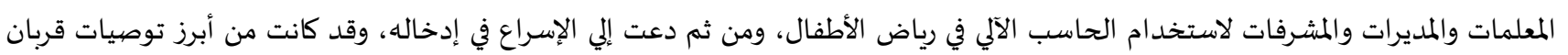

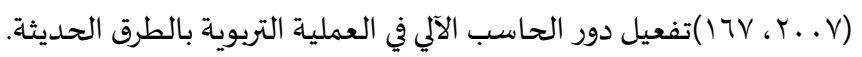

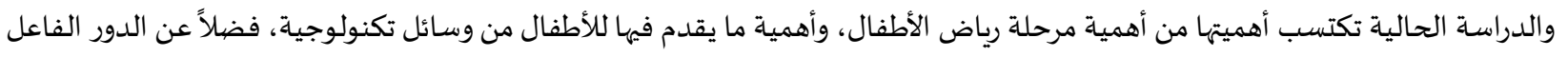

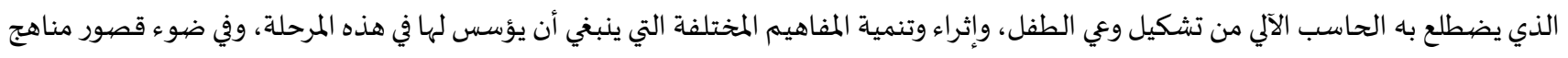

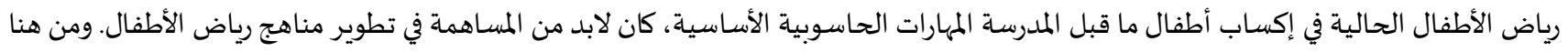

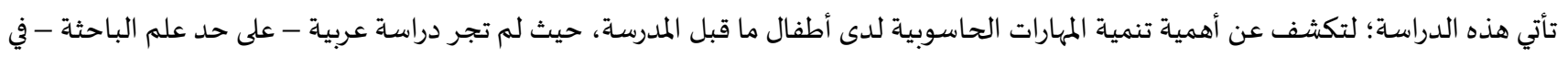
إعدادوحدة تعليمية لتنمية المهارات الحاسوبية للأطفال.

الإحساس بالمشكلة:

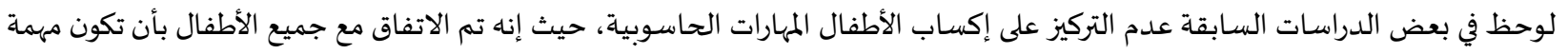

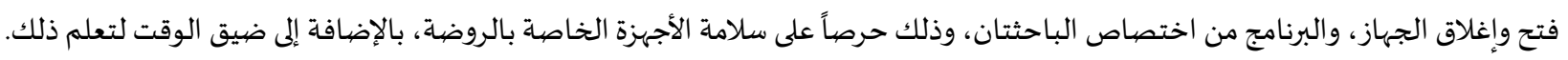


ولذلك؛ سيتم إعداد الوحدة التعليمية للأطفال من ه-7 سنوات؛ لأن القدرة على التركيز في هذه المرحلة تكون أكبر في هذه المرحلة من المراحل التي

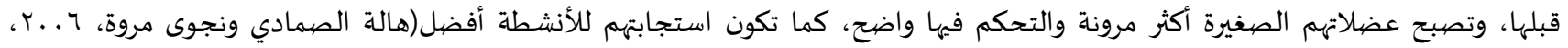
(7V ونسبة حضور الأطفال في هذه المرحلة أكثر من غيرها.

مشكلة الدراسـة:

تتحدد مشكلة الدراسة في عدم وجود وحدة تعليمية للحاسوب في برامج رياض الأطفال، وسعياً من البحث الحالي للإسهام في حل هذه المشكلة تحاول الباحثة الإجابة عن السؤال الرئيس التالي:

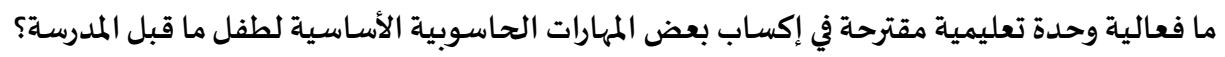
ويتفرع عن هذا السؤال الرئيس الأسئلة التالية:

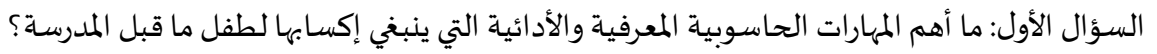
السؤال الثاني: ما مستوى أطفال ما قبل المدرسة - عينة البحث- في تلك المهارات؟ الماته

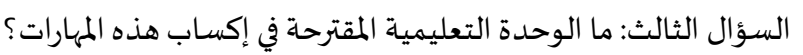

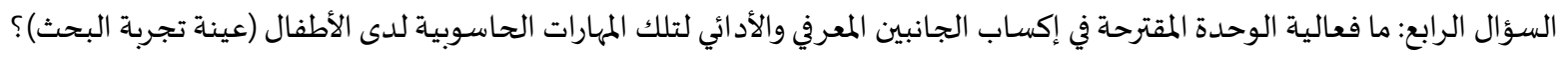
السؤال الخامس: هل يوجد فروق ذات دلالة إحصائية في اكتساب المهارات الحاسوبية للجانبين المعرفي والأدائي يعزى للجنس (ذكر، إنسئ أنثى)

فروض الدراسة:

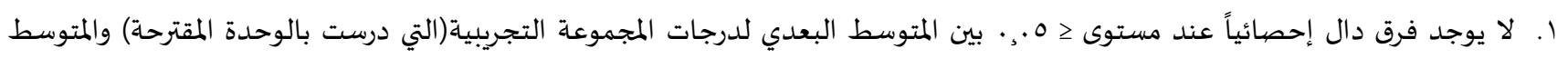

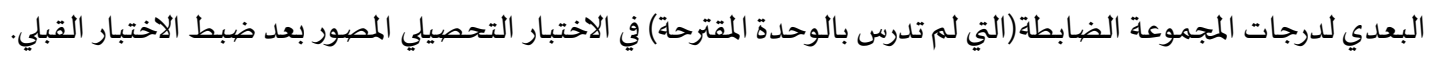

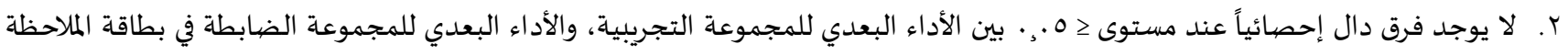
بعد ضبط الملاحظة القبلية.

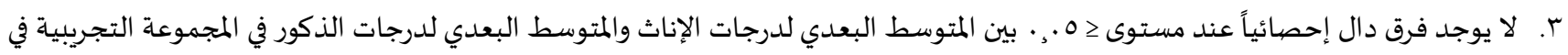

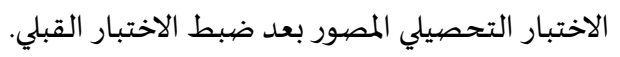

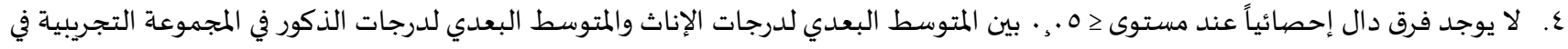

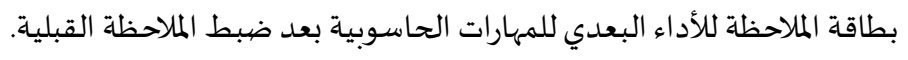

أهداف الدراسة: تهدف الدراسة إلى محاولة تطوير برامج رياض الأطفال في مجال تقنية الحاسب الآلي وذلك من خلال:

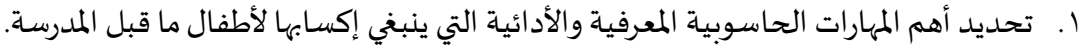

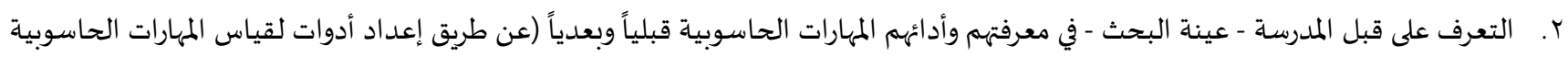
(بطاقة الملاحظة والاختبار التحصيلي المصور).

r. إكساب تلك المهارات من خلال وحدة تعليمية مقترحة (وحدة الحاسب الآلي) من إعداد الباحثة. ع. قياس فعالية تلك الوحدة على الجوانب المعرفية والأدائية. 0. الكشف عن الفروق بين الجنسين (ذكور وإناث) في اكتساب المهارات الحاسوبية في رياض الأطفال.

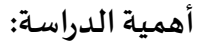

تتمثل أهمية الدراسة في أنها:

ا. تتوافق مع خطط إدارات رياض الأطفال في إدخال الحاسب الآلي بها، والسعي إلى توفير بعض الأجهزة ومحاولة استخد امها r. . تتوافق مع رغبة أولياء الأمور الملحة في محو الأمية التقنية للأطفال في هذه المرحلة المهمة من حياتهم.

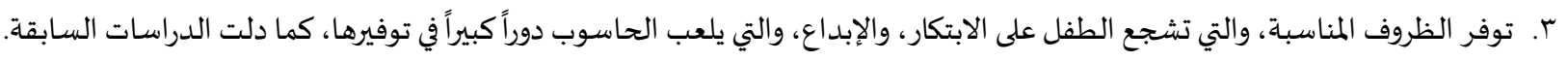

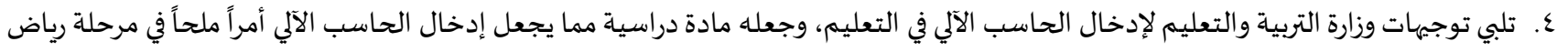

الأطفال. 
0 . مرونة وضع البرامج المنهجية، والأنشطة المقدمة لأطفال رياض الأطفال وطبيعة تكوين الفصل من حيث احتوائه على الأركان المختلفة، الأمر الذي يسهل إمكانية إضافة الأنشطة الحاسوبية بشكل سلس لا يمثل تغيرا كبيرا لطبيعة برامجها، بل يمثل إثراء لها، ويساعد على توضيحها، وتحسن تقدمها. 7. قد تعطي هذه الدراسة مؤشرات للقيام ببحوث أخرى مماثلة في فئات عمرية مختلفة، وقد تسهم في إثراء البحوث والدراسات في مجال تقنيات

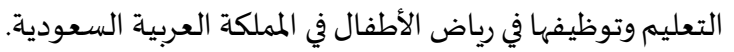

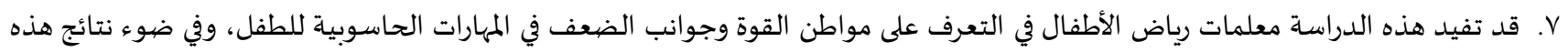

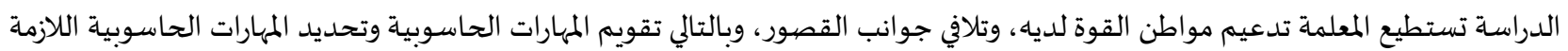
لأطفال رياض الأطفال.

^. قد تفيد نتائج هذه الدراسة وتوصياتها، أصحاب القرار والتخطيط والتنفيذ والتطوير برياض الأطفال بتبني الأصلح منها، مما يسهم في إعداد جيل

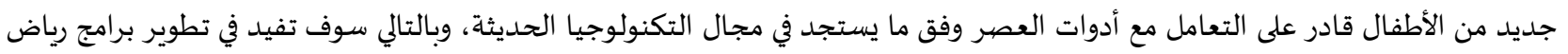
الأطفال مبنياً على نتائج البحث العلمي. 9 9. تعزز هذه الدراسة من قدرات الأطفال على التعلم بواسطة التقنيات الحديثة، وذلك لأهمية الدور الذي تلعبه تقنيات المعلومات في حياة أطفالنا منذ عمر مبكر. • ا.توفير خلفية نظرية وعملية للمشرفات التربويات في رياض الأطفال لتقديم الحلقات التنشيطية للمعلمات في مجال المهارات الحاسوبية. 11 إضافة وحدة الحاسب الآلي لمنهج الوحدات التعليمية في رياض الأطفال. حدود الدراسـة: سوف تلتزم الباحثة بالحدود التالية في دراستها:

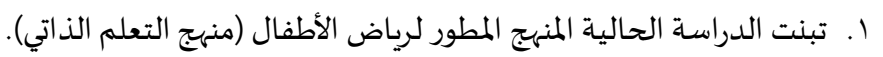

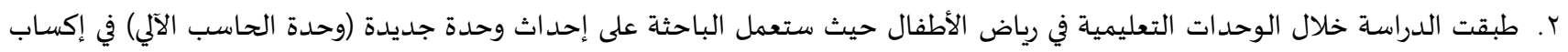

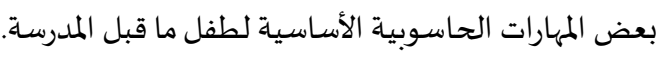

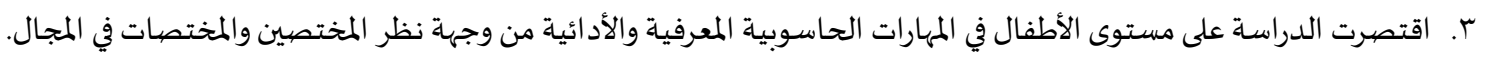

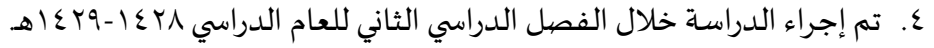

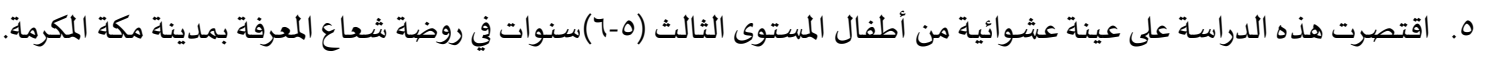

مصطلحات الدراسـة: • فعالية Effectiveness: الأثر المرغوب من البرنامج في تحقيق أهد افه وتحقيق أهداف وحاجات الأفراد الاجتماعية والنفسية والمادية (الحراحشة،

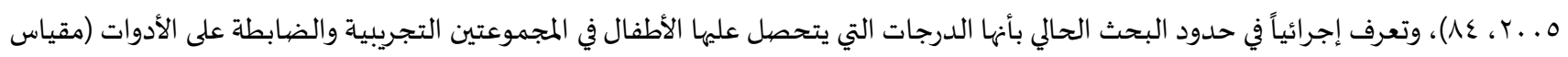

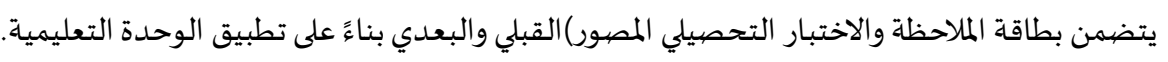
•الوحدات التعليمية Instructional Modules: تنظيم خاص في مادة الدراسة، وطريقة في التدريس، تضع التلاميذ في موقف تعليمي متكامل، يثير

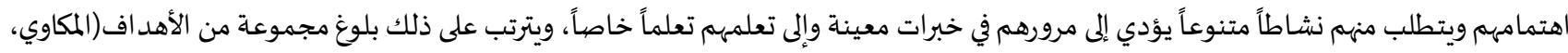

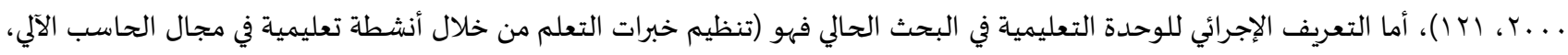

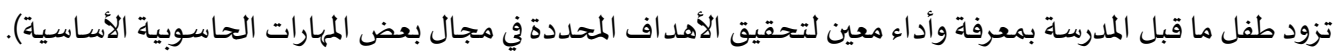

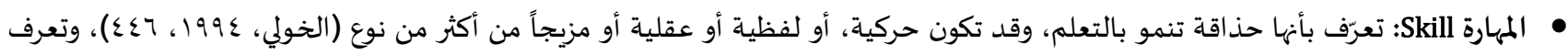

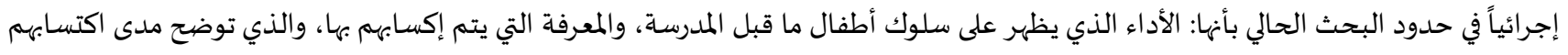

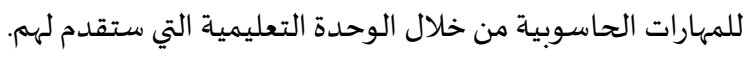

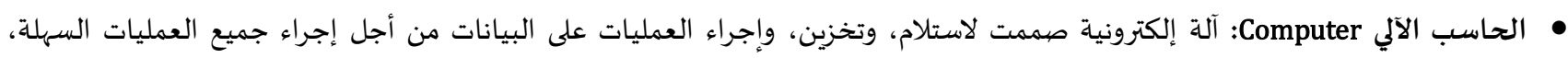

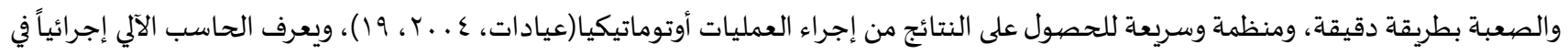

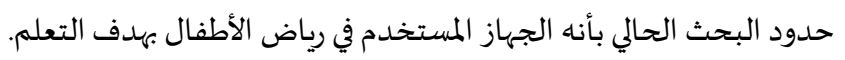
• المهارات الحاسوبية: قسمت الباحثة المهارات الحاسوبية إلى قسمين وعرفتها كالتالي: 
المهارات الأدائية: أداء أطفال ما قبل المدرسة وقدرتهم على استخدام الحاسب الآلي (فتح وإغلاق الحاسب الآلي - استخدام الفأرة- استخدام لوحة المفاتيح-استخدام البرمجيات)والذي يظهر على سلوكهم من خلال بطاقة الماتلاحظة.

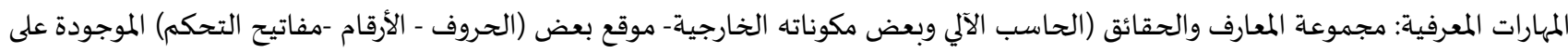

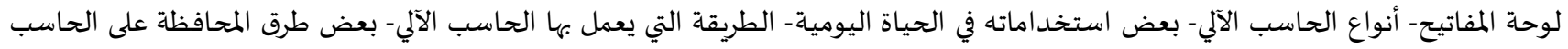

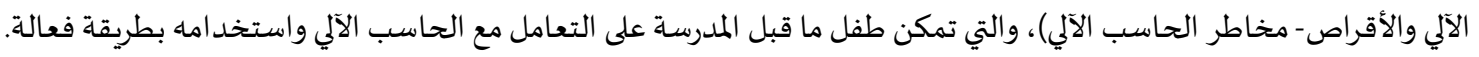

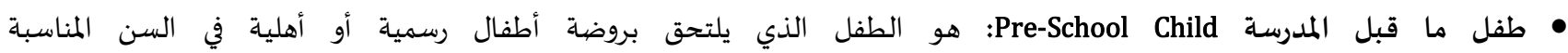

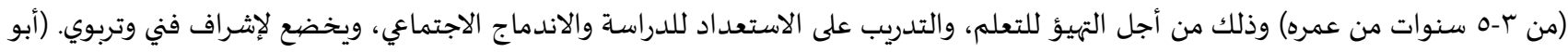

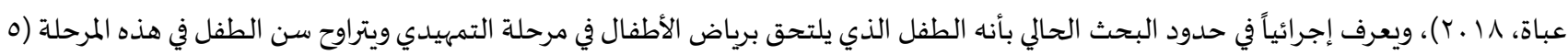
(1) 7 سنوات).

\section{الإطار النظري}

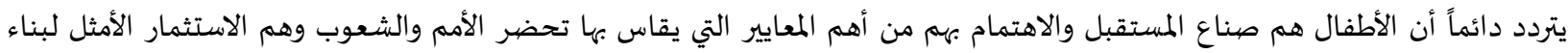

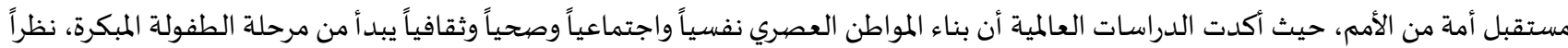

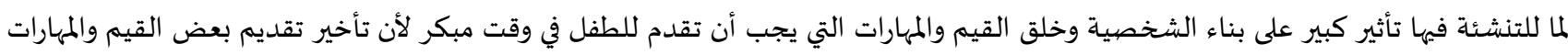

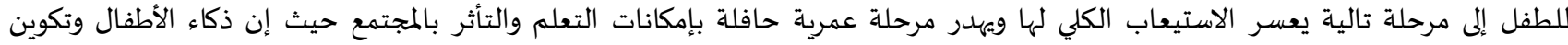

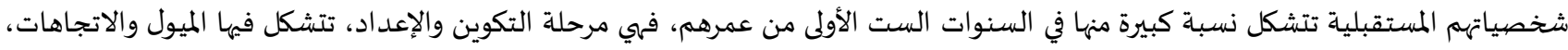

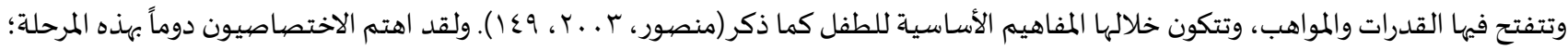

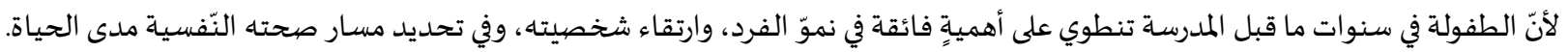

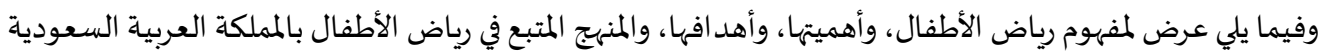

مفهوم رياض الأطفال Kindergartens:

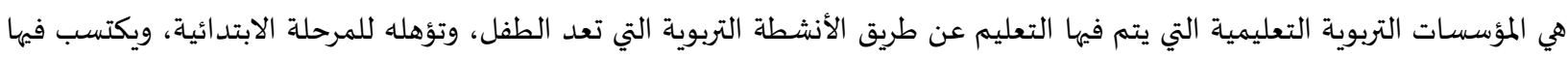

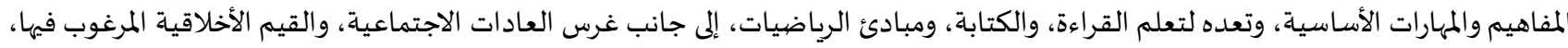

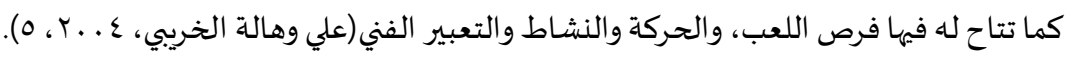

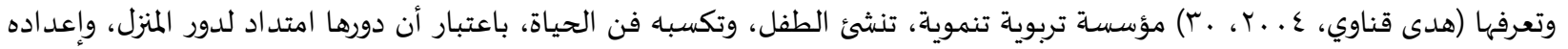

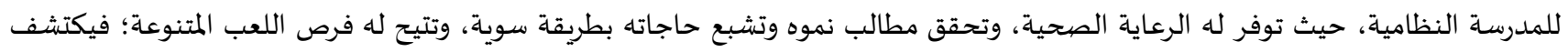

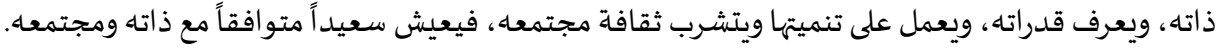

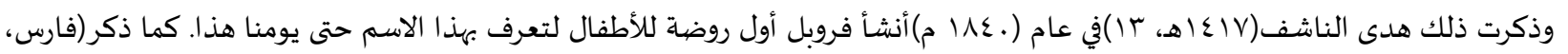

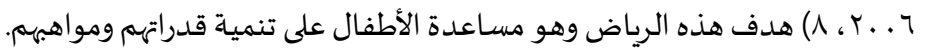

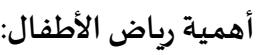

تنبع أهمية رياض الأطفال من أهمية مرحلة الطفولة المبكرة حيث إنها مرحلة حاسمة في تشكيل أساسيات الشخصية ومسار نموها، ولها أهميتها

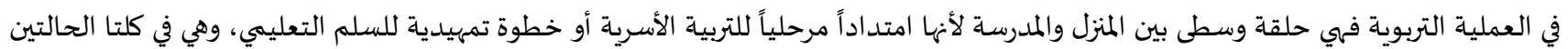

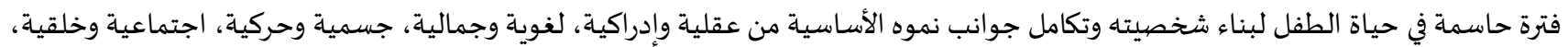

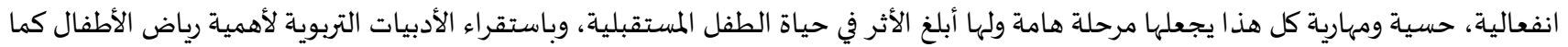

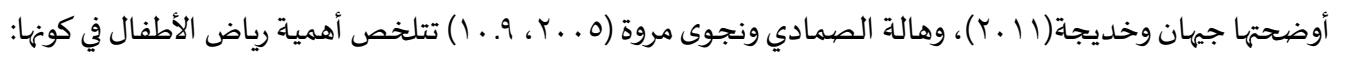

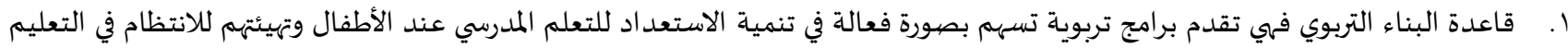

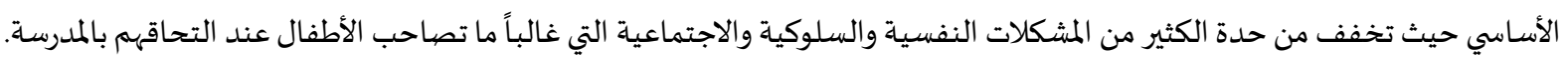

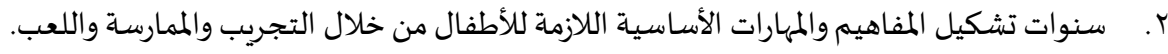

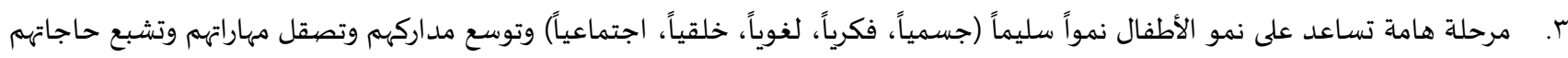
المختلفة، وتوجه ميولهم بالشكل الصحيح. ع. تزود الأطفال في سن مبكرة بالقيم والاتجاهات والمبادئ التي يؤمن بها مجتمعهم، وتكسبهم العديد من العادات الجيدة مثل النظام، والنظافة،

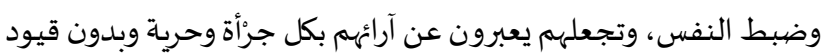




$$
\text { 0. مرحلة الإبداع والابتكار، فالطفولة المبكرة هي مرحلة تفتح هذه القدرات. }
$$

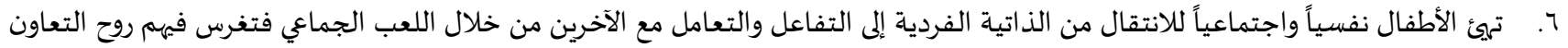
واحترام ملكية الآخرين. V. مرحلة مرنة، يكون الأطفال فيها أكثر استجابة لتعديل سلوكهم، فالأطفال في حالة من التشكيل والتكوين وهم لذلك قابلون للتغير والتعديل أكثر من أي مرحلة نمائية أُخرى.

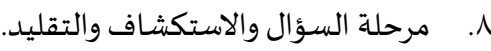

9 ه. من أهم الأسباب التي أعطت لرياض الأطفال أهمية كبيرة خروج المرأة للعمل، مما جعلها غير قادرة على التنسيق بين عملها وكثير من واجباتها

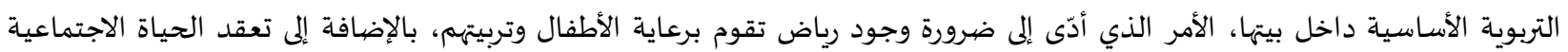

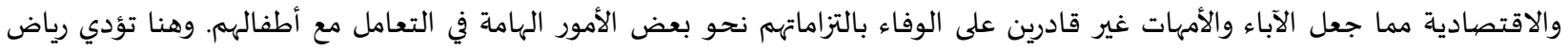

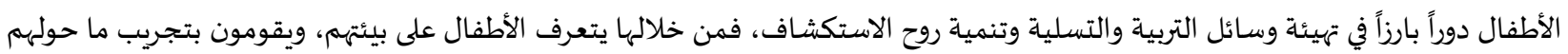

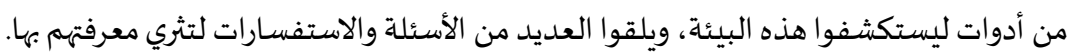

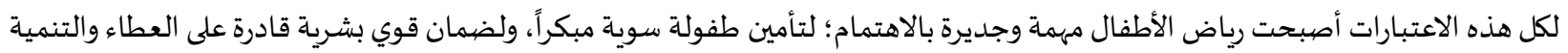
مستقبلاً؛ لذلك اهتمت حكومة المملكة العربية السعودية بدعم رياض الأطفال من أجل رعاية الطفولة والارتقاء بالمستوى التربوي في البلاد.

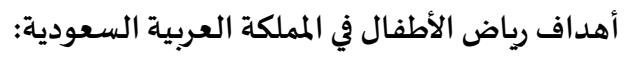
تشكل الأهداف التربوية عادة القاعدة الأساسية التي يتم في ضوئها اختيار المدخلات التعليمية من حيث، مضمونها وأنشطتها وأساليهها وطرائق

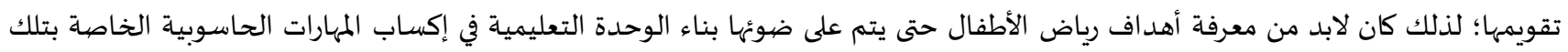
المرحلة.

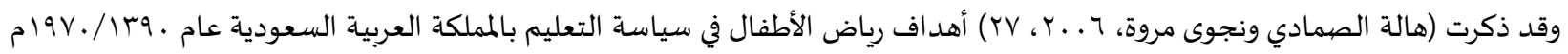
كما يلي: ا. صيانة فطرة الطفل، ورعاية نموه الخلقي والعقلي والجسمي في ظروف طبيعية سوية مشابهة لجو الأسرة، متجاوبة مع مقتضيات الإسلام. r. ت تكوين الاتجاه الديني القائم على التوحيد، المطابق للفطرة.

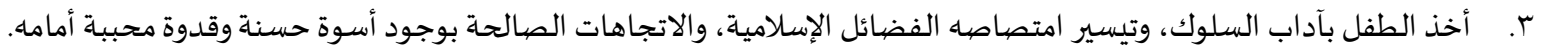
ع. إيلاف الطفل الجو المدرسي، وتهيئته للحياة المدرسية، ونقله برفق من الذاتية المركزية إلى الحياة الاجتماعية المشتركة مع أتراباه. 0. تزويد الطفل بثروة من التعبيرات الصحيحة والأساسيات الميسرة والمعلومات المناسبة لسناه والمتصلة بما يحيط بـاه.

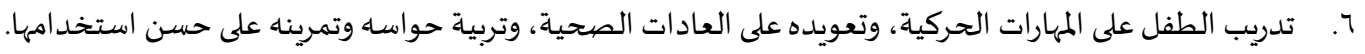
V. تشجيع نشاطه الابتكاريّ، وتعهد ذوقه الجمالي، واتاحة الفرصة أمام حيويته للانطلاق الموجها. 1. الوفاء بحاجات الطفولة، وإسعاد الطفل، وتهذيبه في غير تدليل ولا إرهاق.

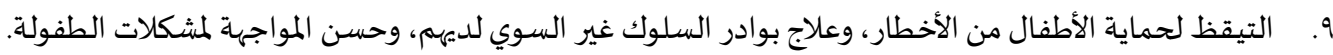
المنهج المتبع في رياض الأطفال بالمملكة العربية السعودية:

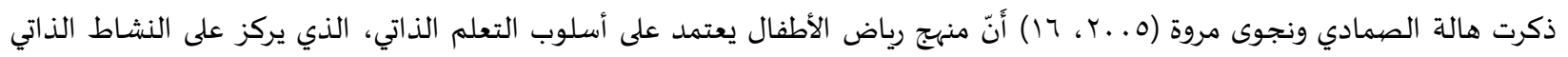

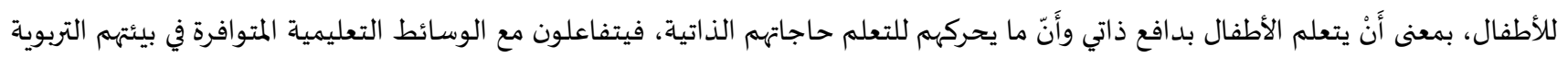

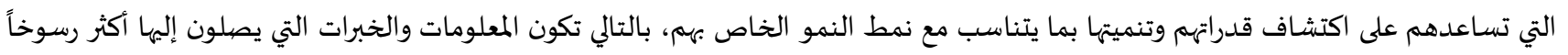

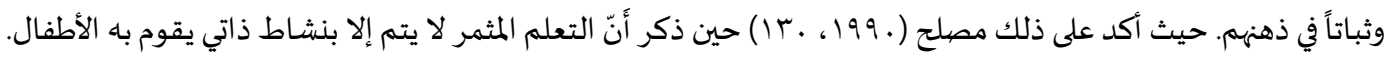

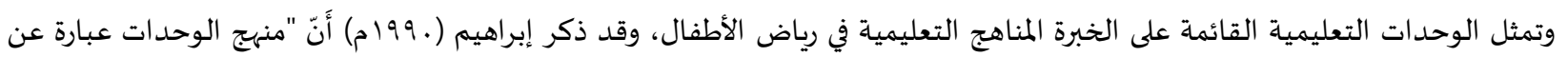
تنظيم خاص في المادة الدراسية، وطريقة التدريس تضع الأطفال في موقف تعليمي متكامل يثير اهتمامهم، ويتطلب منهم نشاطاً متنوعاً يناسبهم، ويراعي ونئي

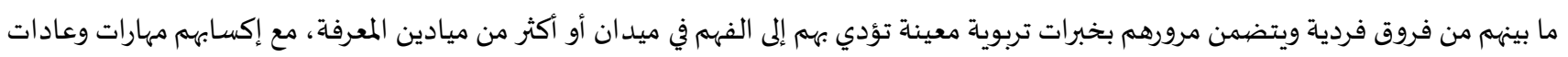
واتجاهات وقيم مرغوب فيها. اتفق التربويون القائمون على العملية التعليمة في رياض الأطفال على مواضيع الوحدات التعليمية، ومحتواها لتفي بحاجات الأطفال وإثارة

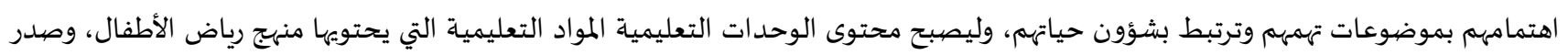

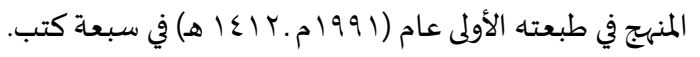


استعمال المعلمة للوحدات التعليمية:

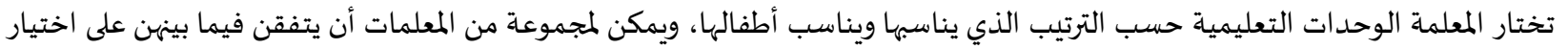

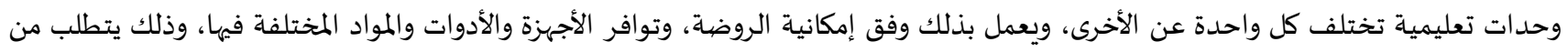
إدارة الروضة تنظيماً وتنسيقاً رفيع المستوى لمساعدة كل معلمة ودعمها على تحقيق أهدافها، مع مراعاة التوازن والتكامل والترابط بينها وبين زميلاتها

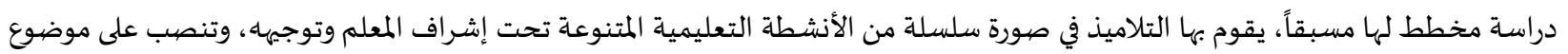

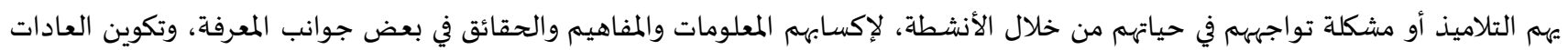

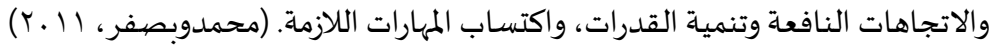

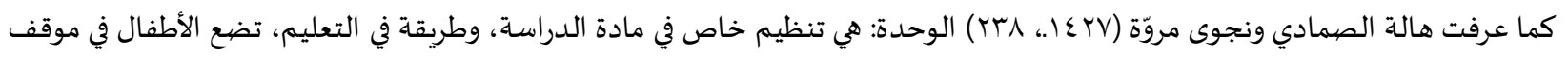

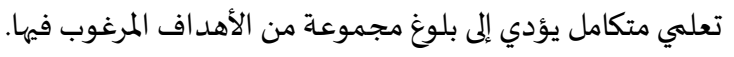

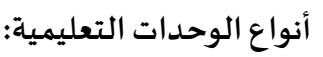

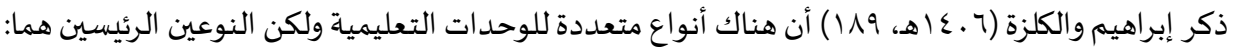

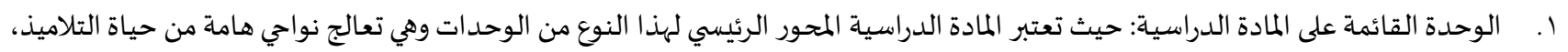

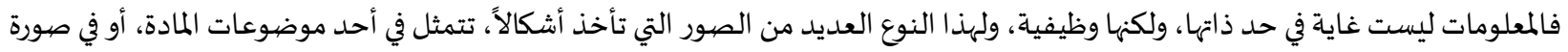

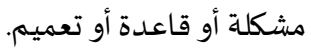
r. . الوحدة القائمة على الخبرة: يكون محورها حاجات التلاميذ وميولهم ومشكلاتهه.

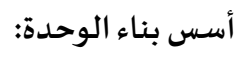

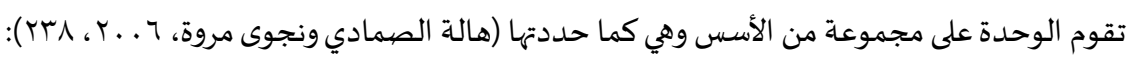

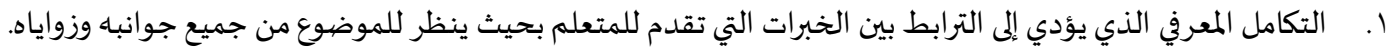

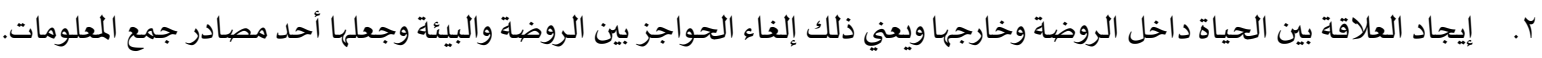

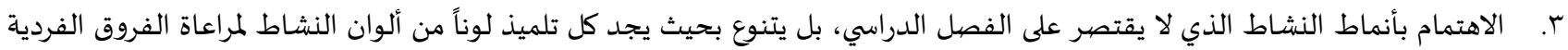
بينهم. ع. تحقيق مبدأ شمول الخبرة حيث يتم الاهتمام بجوانب الخبرة المتعددة التي تتمثل في المعلومات والاتجاهات والمهارات والميول والتفكير وأوجه التقدير. 0. التقويم في ضهوء أسسـا العلمية السليمة فيكون التقويم مصياحباً لعملية التعلّم بصورة مستمرة، ويكون في الوقت نفسـه شاملاً لجوانب الوحدة. خطوات بناء الوحدة التعليمية: حتى يتم تنفيذ الوحدة التعليمية بفائدة كبيرة للأطفال يجب بناءها بتتبع الخطوات الصحيحة، التباءة والتي تكون خطة متكاملة لبناء الوحدة،

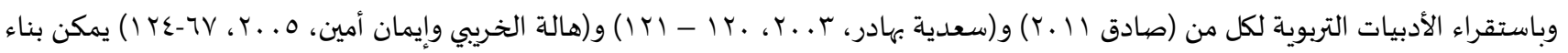
الوحدة التعليمية تعرضها الباحثة باتباع الخطوات التوات التالية: أولاً: اختيارموضوع وعنوان الوحدة:

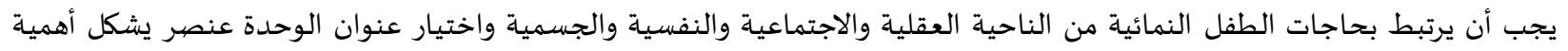

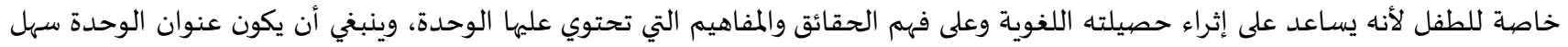

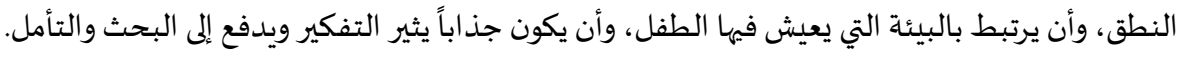
ثانياً: مقدمة الوحدة:

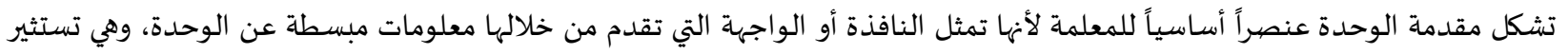

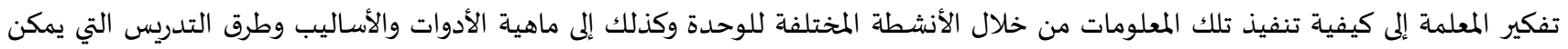

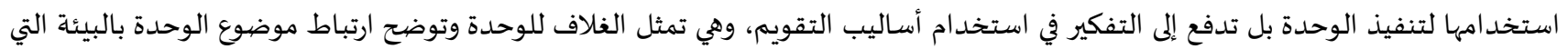

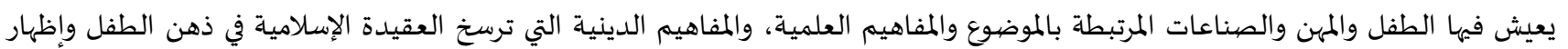

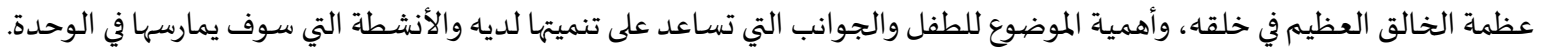

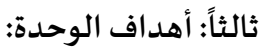


اهتم علماء النفس والتربويون بتنصيف الأهداف حيث إن الغرض منها هو مساعدة المعلم على توفير أفضل ظروف التعلم للطفل حتى يتعلمها

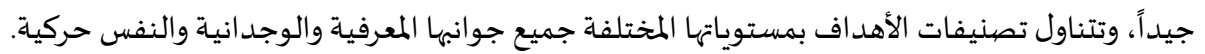

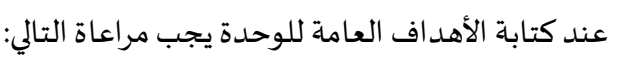

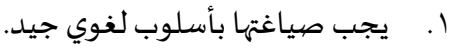
r. إيجاز العبارة ودقة التعبير. ب. يجب شمولها على كافة مظاهر النمو لدى الطفل (الجسمي - العقلي - الانفعالي - الاجتماعي). ع. توحي للمعلمة بمفاهيم الوحدة. 0. تساعد المعلمة على تحديد الأنشطة الفعالة لتنفيذ الوحدة. تحديد الأهداف السلوكية الإجرائية: وهي تمثل المتوقع من الطفل أداؤه بعد ممارسة الوحدة، ونلاحظ أن الأهد اف السلوكية الإجرائية هي أهداف

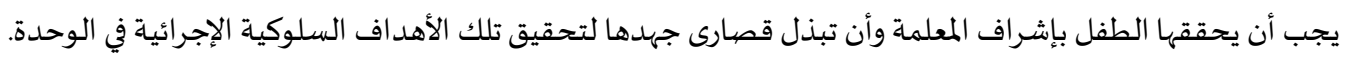

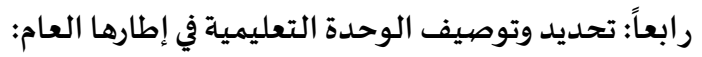

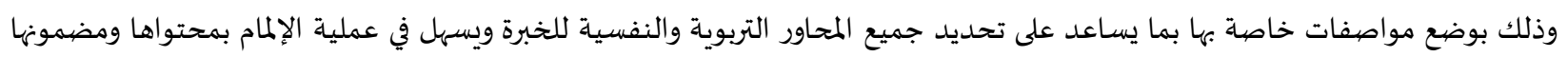
ومكوناتها وعناصرها الرئيسية والفرعياة، وبذلك يكون من السهل الانتقال للمرحلة التالية وهي تحليل المحتوى إلى عدد من المفاهيم الأساسية.

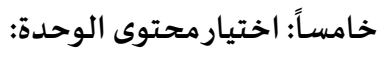
يعد المحتوى أول عناصر الوحدة التعليمية تأثيراً بالأهداف، و هو كل ما يضعاه المخطط من خبرات سواء خبرات معرفية أو انفعالية أو حركية

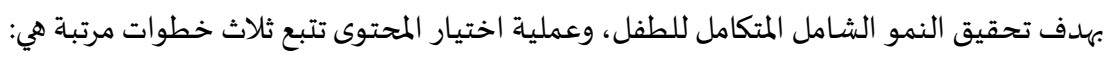

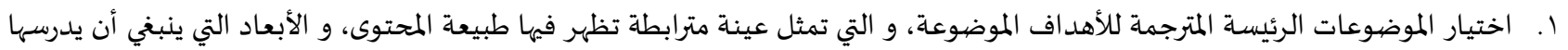

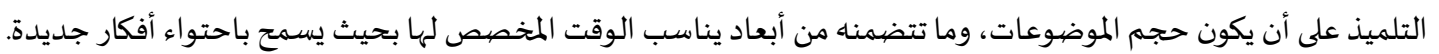

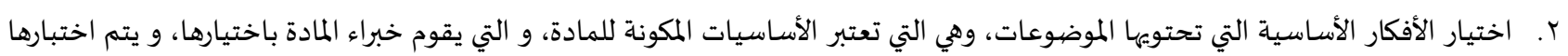

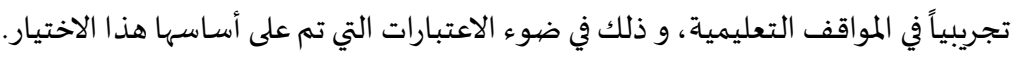

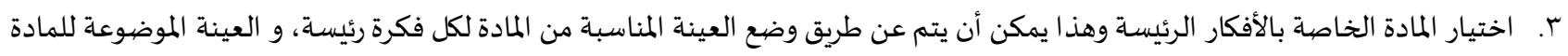

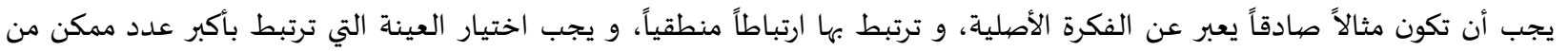

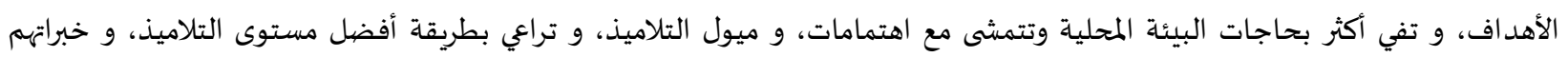
السابقة، و ترتبط بمشكلات حياتهم، و تنمي قدراتهم.

معايير اختيار المحتوى:

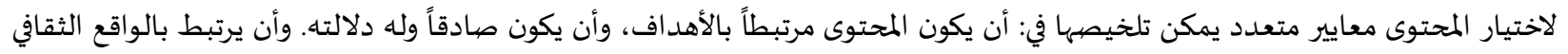

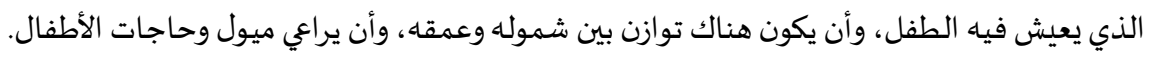

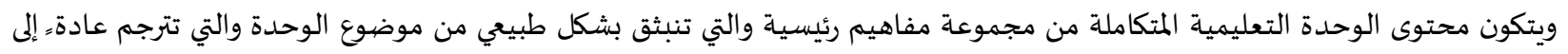

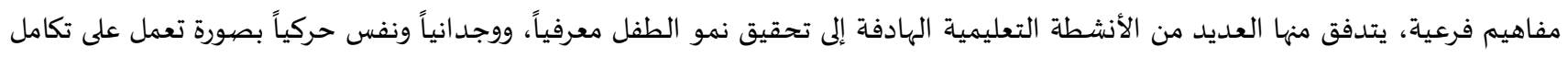
جوانب نموه وشخصيته. ويتب أن يرتبط محتوى المنهج بحاجات الطفل ويعمل على إشباعها حتى تحقق الأهداف، وهناك أهدافاً تربوية تسعى مؤسسات رياض الأطفال

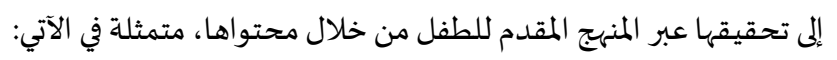
ا. بناء الطفل من الداخل بحيث يكون متمسكاً بالقيم الروحية والأخلاقية.

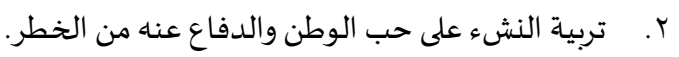

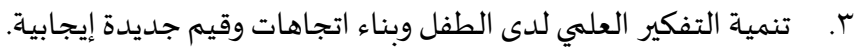

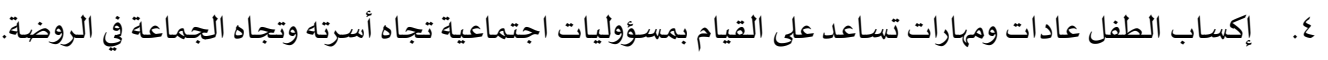
0. تربية الطفل على التعلم الذاتي. كما أن المحتوى لا يعرض منفصلاً بذاته وإنما يعرض متكاملاً مع وسائل تعليمية وأنشطة وتدريبات وأسئلة ويشمل المحتوى على حقائق ومعارف

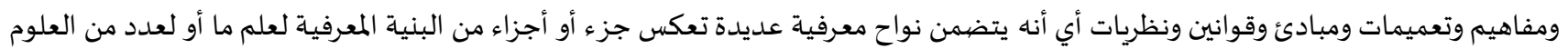
وهذا المحتوى ينظم في شكل يتلاءم مع مستوى دارسي معين ومين ونين. 
عناصرترتيب محتوى الوحدة التعليمية:

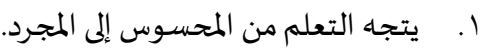

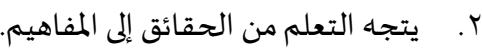

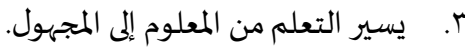
ع. يسير التعلم من التقليد إلى الابتكار.

0. الابد من مراعاة التسلسل المنطقي في ترتيب الحقائق والمهارات. المفاهيم التي يجب تضمينها في الوحدات التعليمية في رياض الأطفال: إن منهج رياض الأطفال يقوم على توفير مختلف الخبرات والتجارب التوحات التي تخدم الطفل وتكسبه الخبرة اللازمة وتعمل على تنميته في مختلف مجالات النمو. وبالتالي فهو يقوم على الحركة واللعب والانطلاق والحرية المنظمة والاستقلالية والبحث والاستكشاف، وهي المعايير التي ترتبط بها عملية

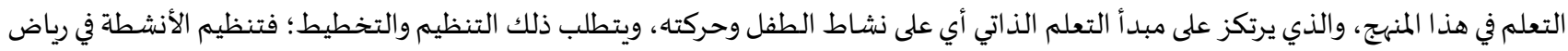
الأطفال تحكماه ضوابط فهو يتطلب تحديد الأهداف ورسم الخطط واختيار الطرائق وإعداد الوسائل، أي أن منهج الأنشطة في الروضة يعني سلسلة

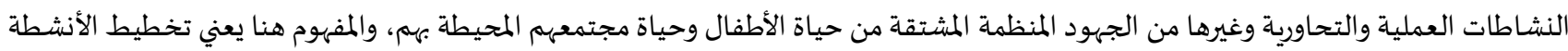
وليس الأنشطة ذاتها فهناك تخطيط للأنشطة اللغوية لتنمية مدارك الأطفال الكلامية والحوارية والأنشطة الدينية التي تشارك في تنمية هذه المدارك والقدرة على التفكير والأنشطة الرياضية وكذلك تخطيط للأنشطة العلمية التي تفتح الأطفال على ما حولهم من مظاهر طبيعية وعلمياة وتنمي فيهم

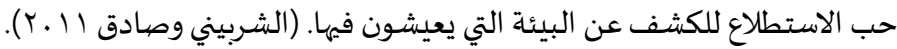

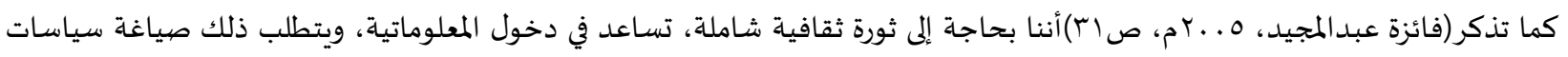

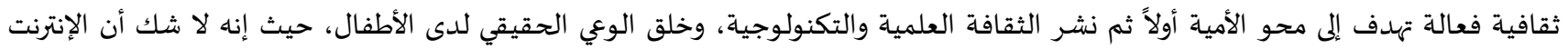

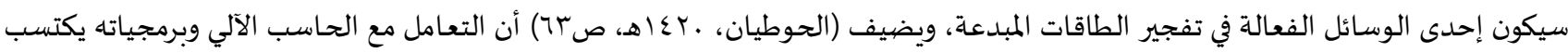

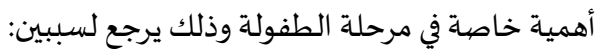
الأول: لأن الحاسب الآلي وسيلة للتعلم والاستفادة ذات اتجاهين، أما الوسائل الأخرى فهي ذات التهات اتجاهو واحد من الوسيلة إلى المستخدم. الثاني: للحاسوب القدرة على المحاكاة (تصوير الواقع)حيث يسهم ذلك في إنجاح عملية الاستفادة منه والتشويق المصاحب لاحب لهاته. ويعد تعليم تكنولوجيا المعلومات والاتصالات مهماً بشكل خاص في دعم نمو (اقتصاد المعرفة) حيث إن الأطفال الذين يتعلمون المهارات الحاسوبية الأساسية سوف يتكيفون بسهولة مع المتغيرات الرئيسية في سوق العمل، ومن ثم سيستفيدون مع ارتفاع الدخل والتمتع بآفاق أوسع

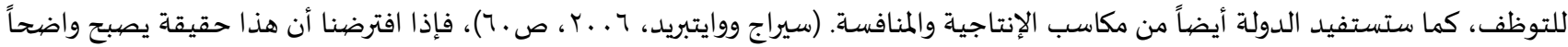

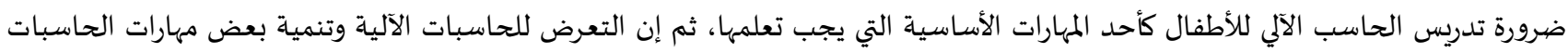

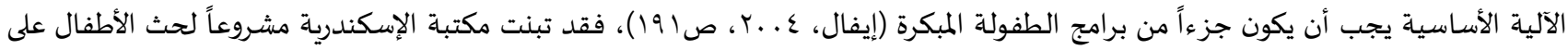

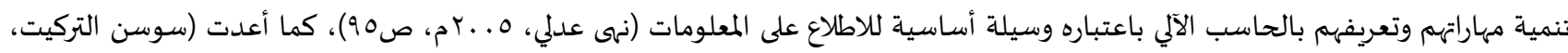

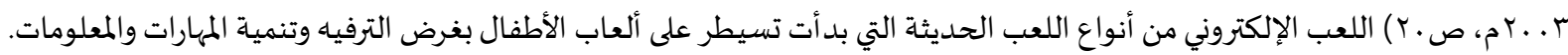
أهمية استخدام الحاسب الآلي للطفل:

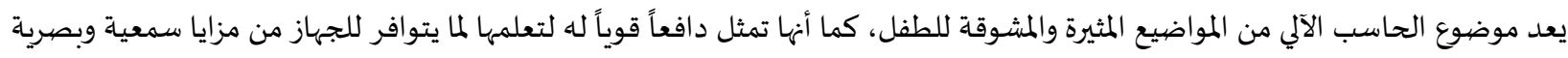

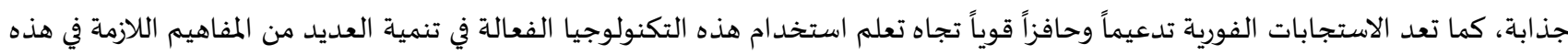

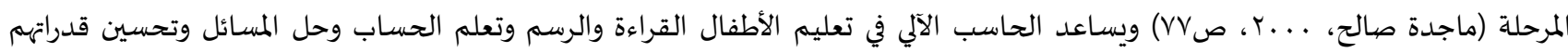

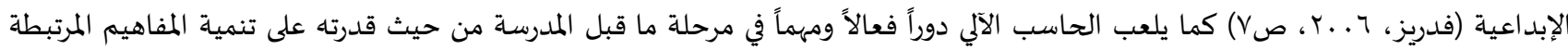

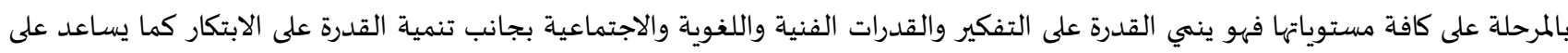

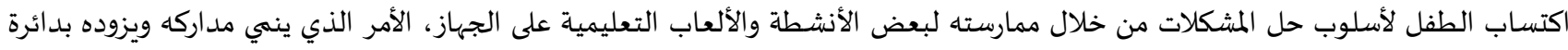

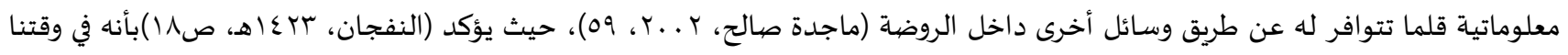

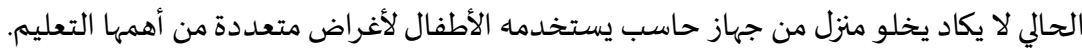

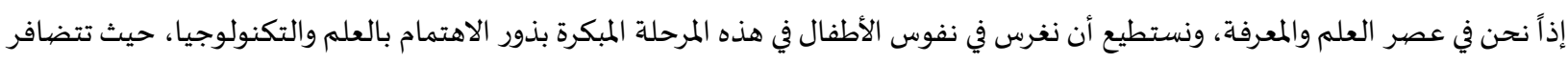

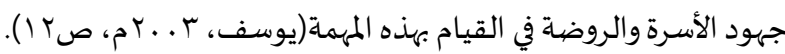

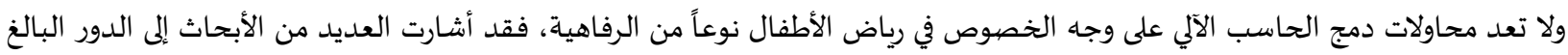

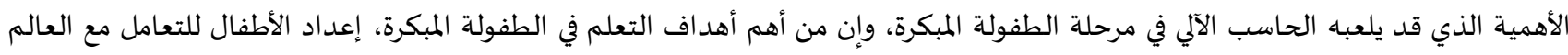




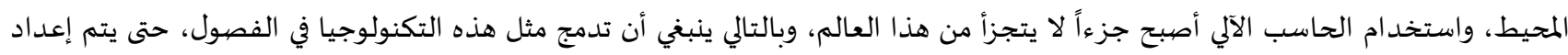

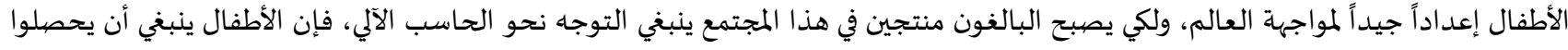

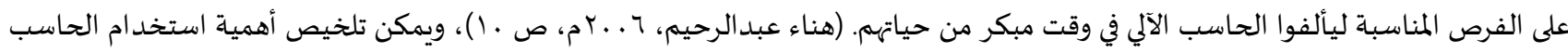

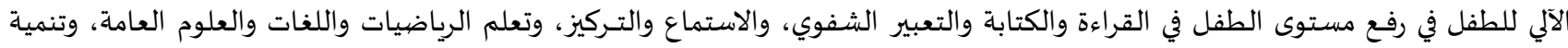

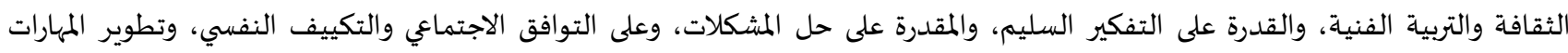

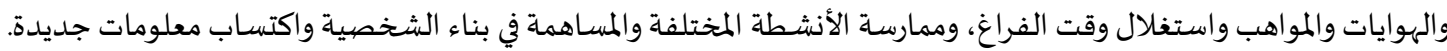

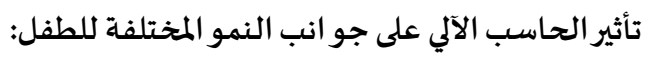

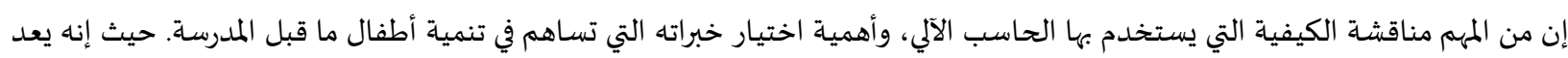

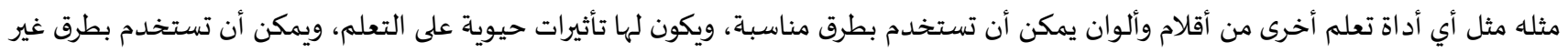

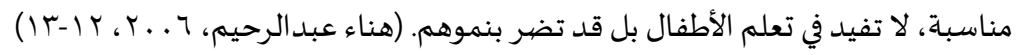

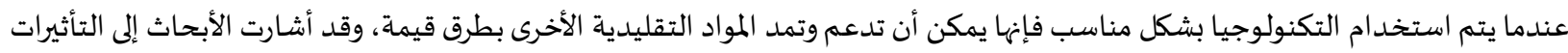

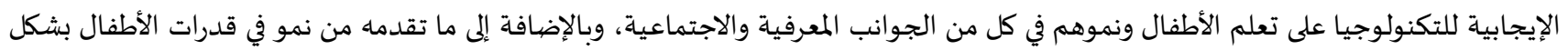

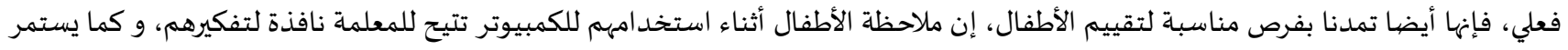

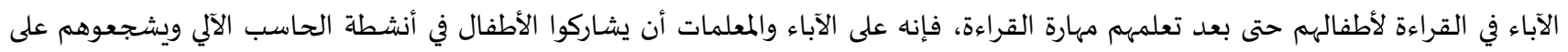

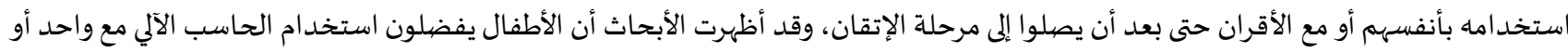

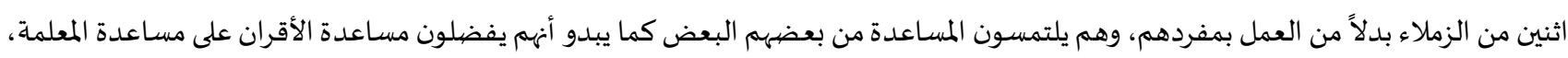

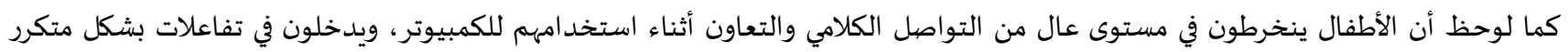

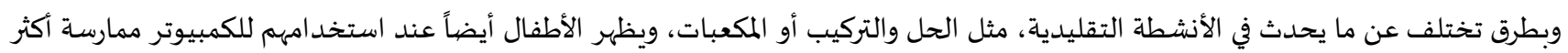

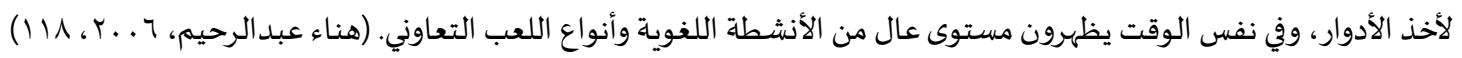

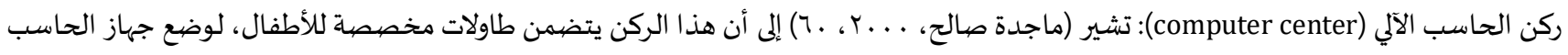

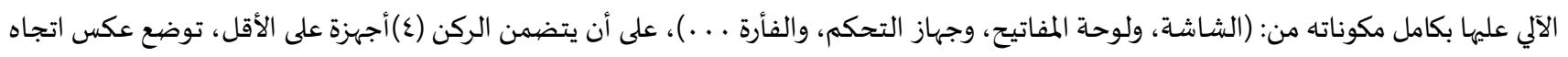

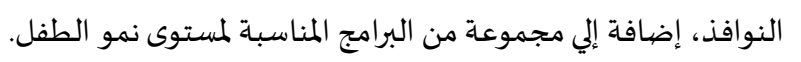

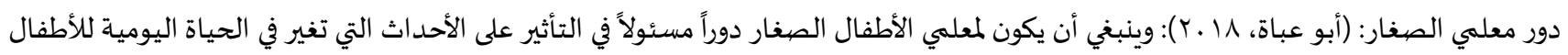

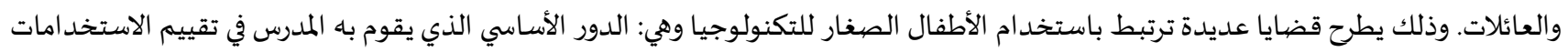

المناسبة للتكنولوجيا.

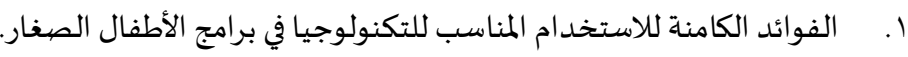

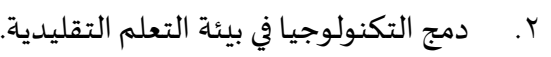

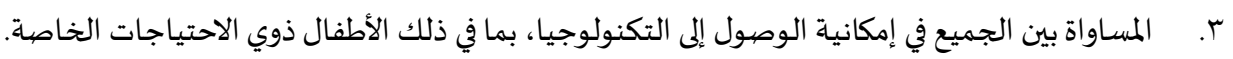

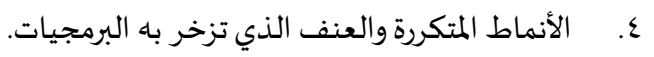

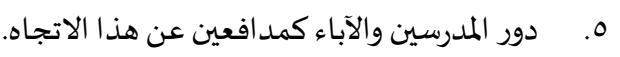

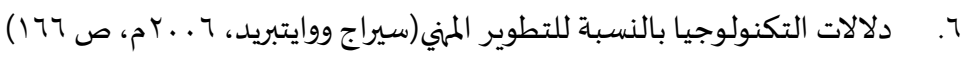

الدراسات السابقة:

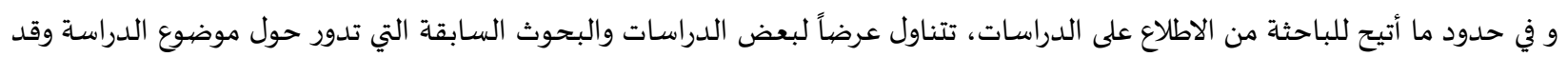

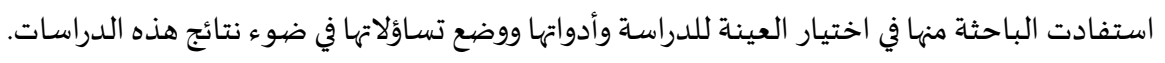

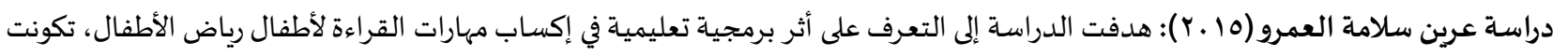

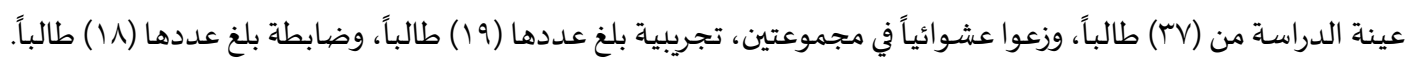

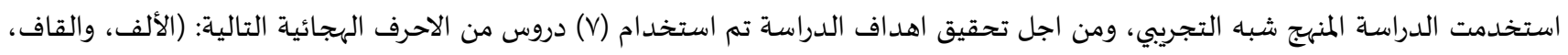

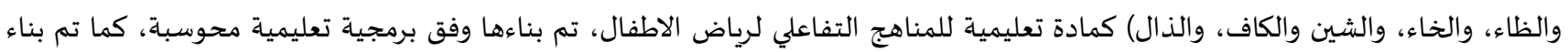

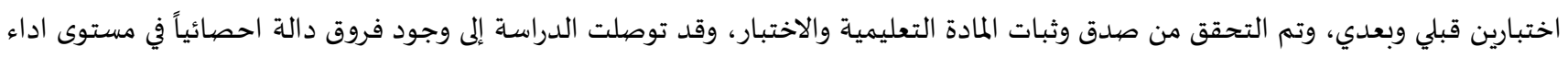

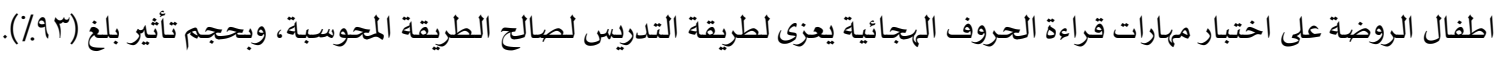


وفي ضوء النتائج اوصت الدراسة بضرورة بناء برنامج تعليمي لرياض الاطفال اعتماداً على منهاج رياض الأطفال التفاعلي، موظفاً البرمجيات التعليمية المحوسبة في تدريسه.

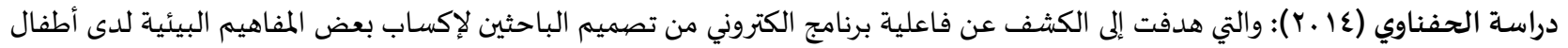

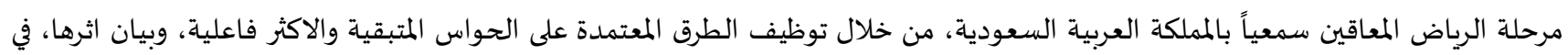

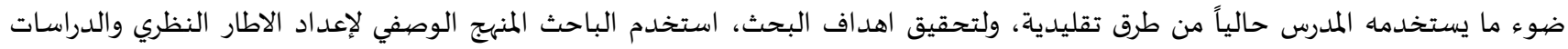

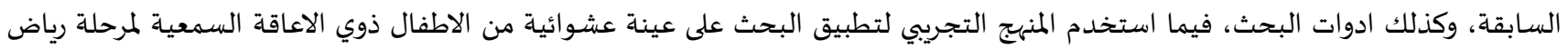

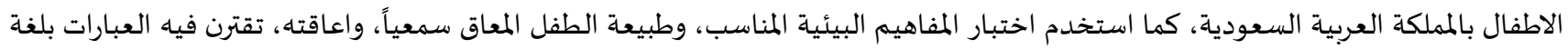

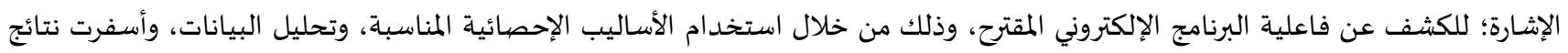

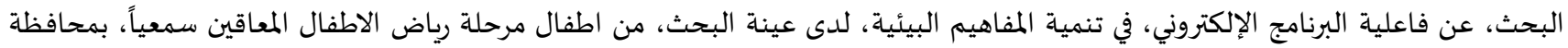

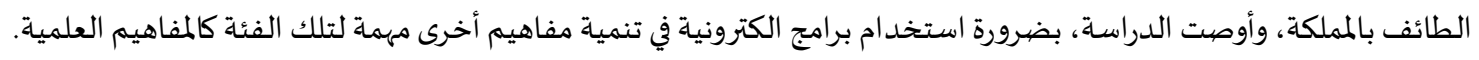

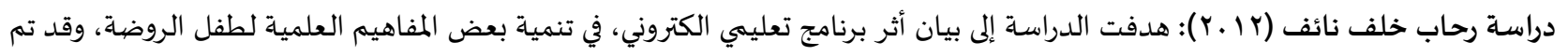

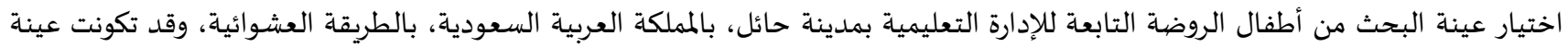

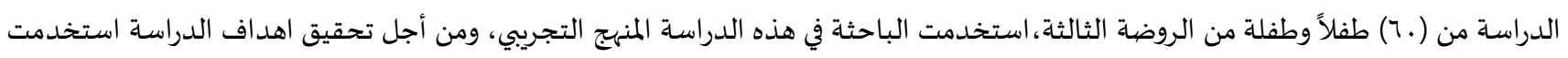

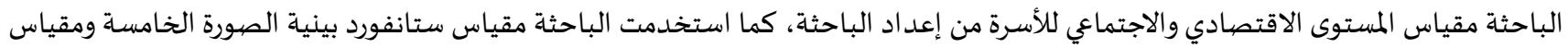

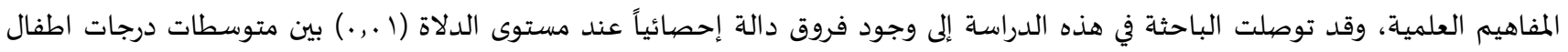

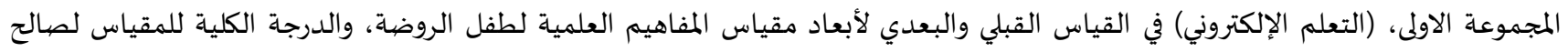

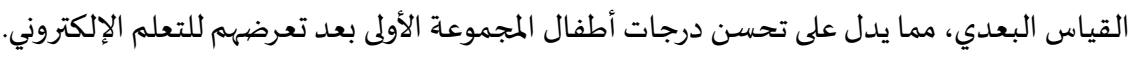

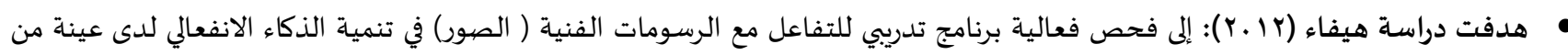

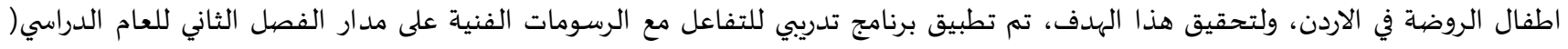

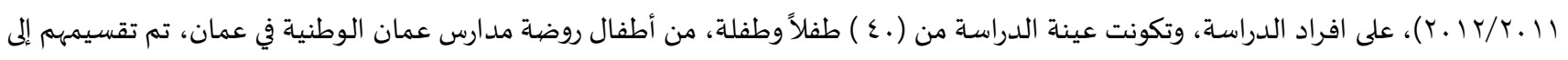

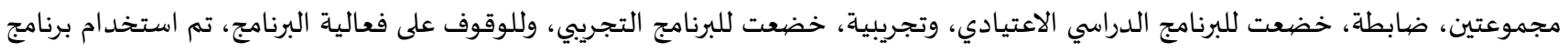

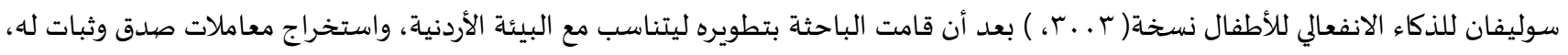

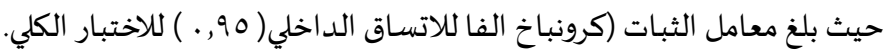

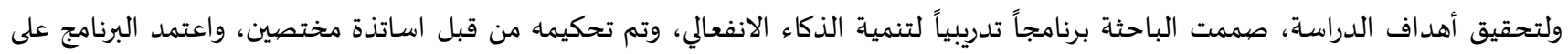

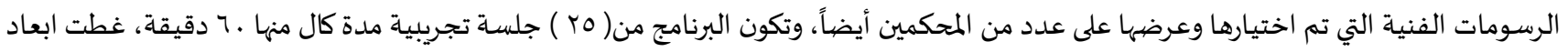

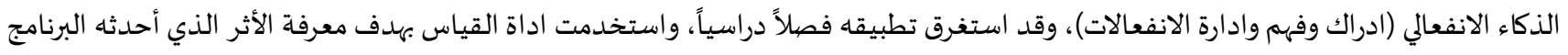

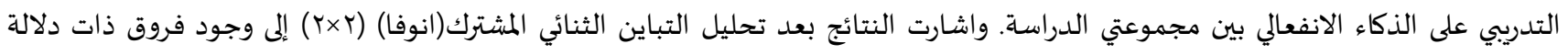

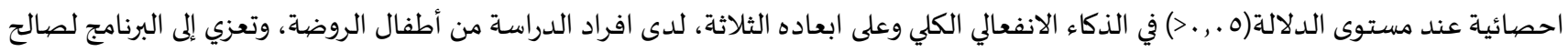

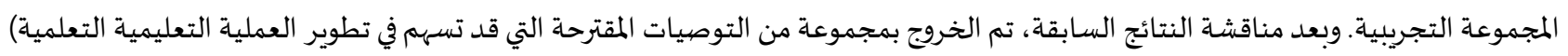

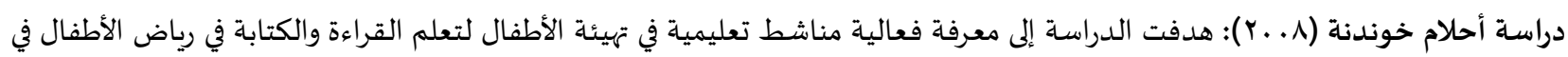

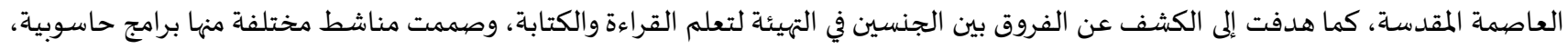

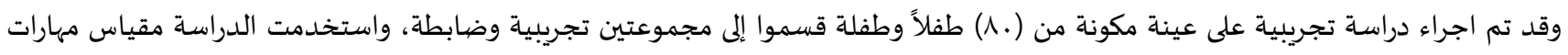

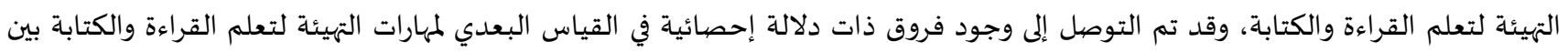

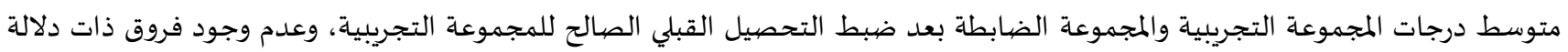

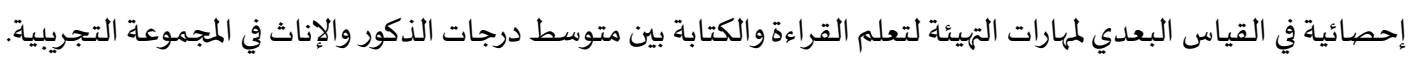

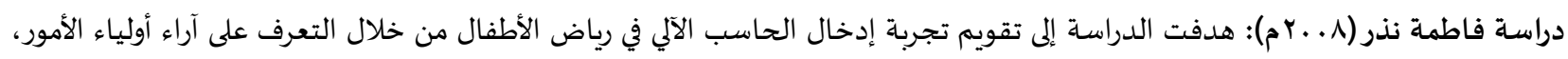

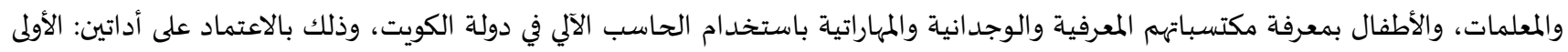

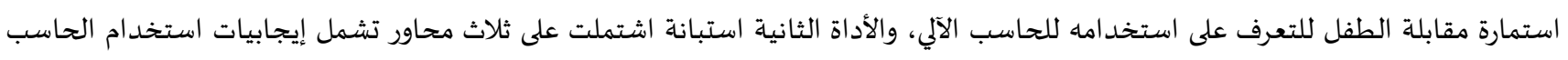

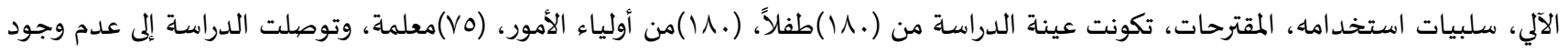

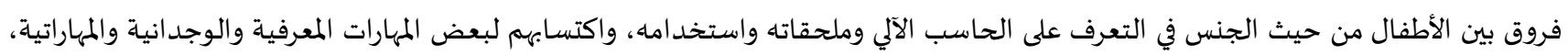


وأسفرت الدراسة على أن المعلمات أكثر إدراكاً لأهمية إيجابيات الحاسب الآلي في رياض الأطفال، واقتراح وسائل وأساليب لتفعيل تجربة استخدامها

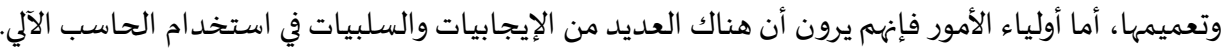

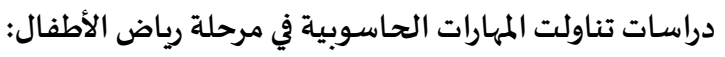

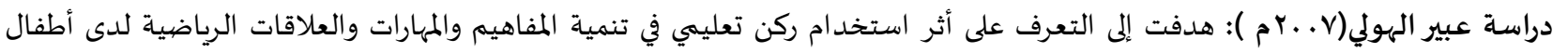

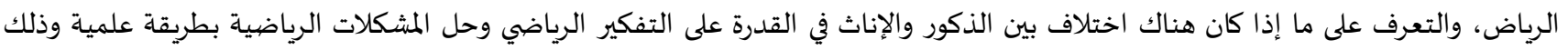

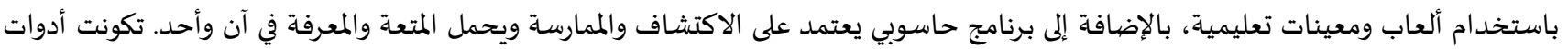

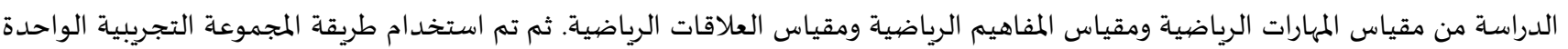

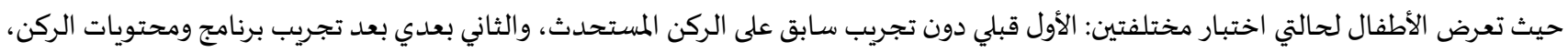

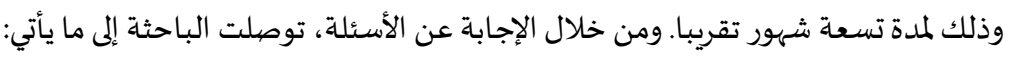

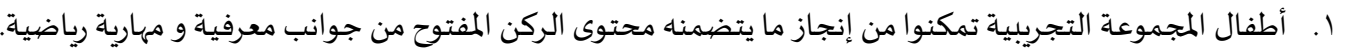

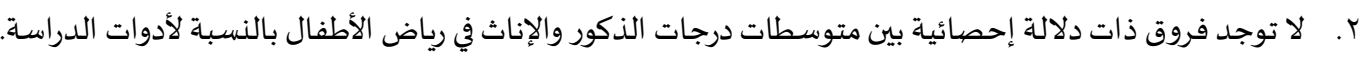

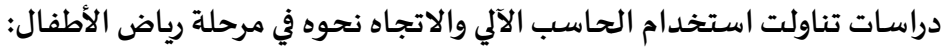

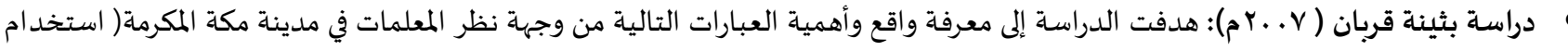

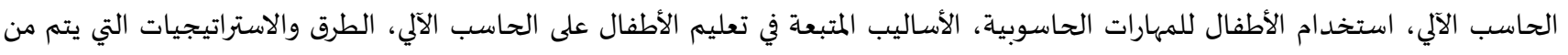

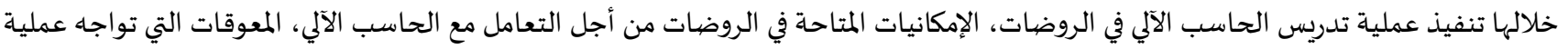

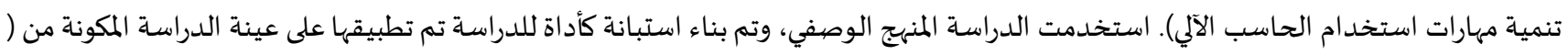

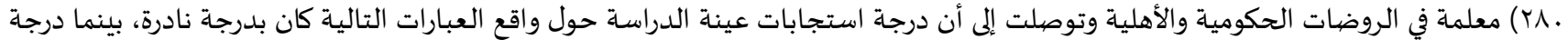

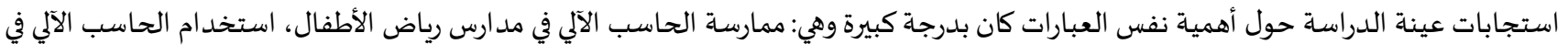

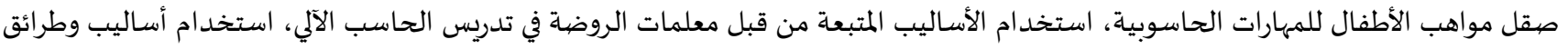

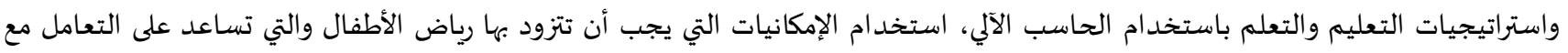

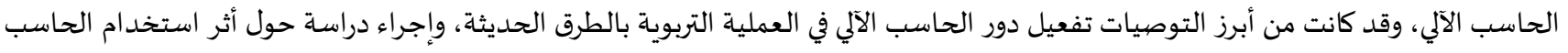

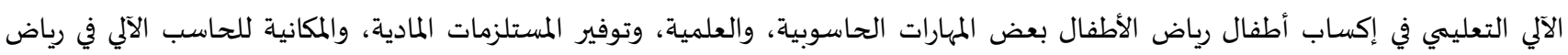
الأطفال. • دراسة باتسي وديفيد وآخرون(Patsy \&David \&others,2004): هدفت الدراسة إلى وصف تقدم وتطور المعرفة والمهارات في ستة مبادئ: القضايا

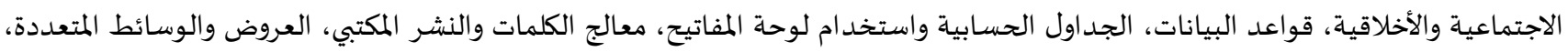

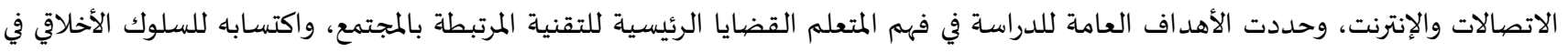

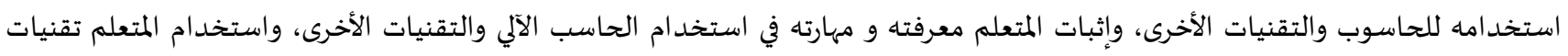

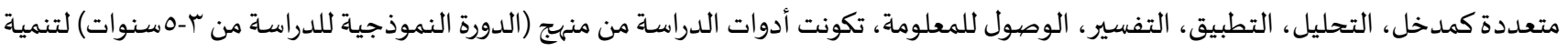

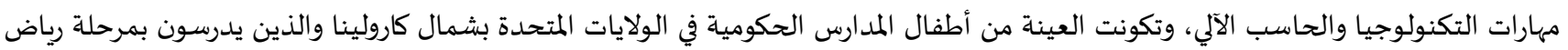

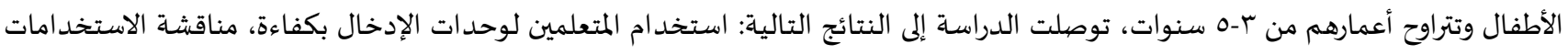

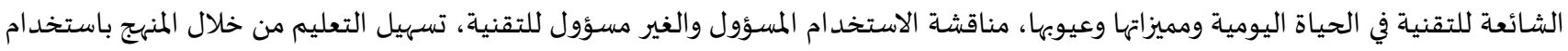

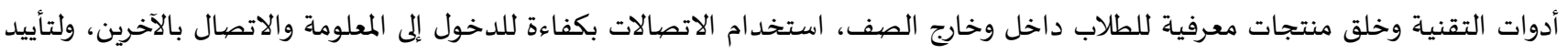

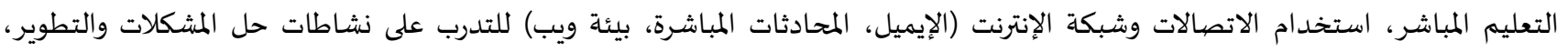

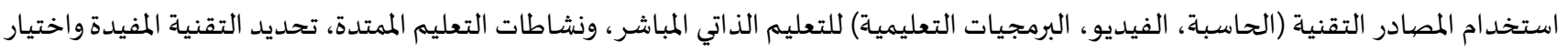

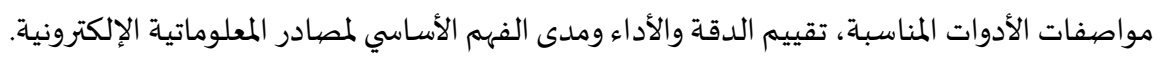
التعقيب على الدراسات السابقة:

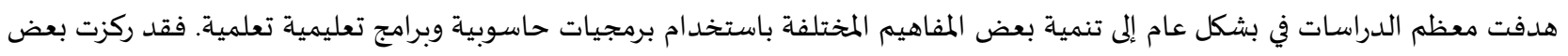

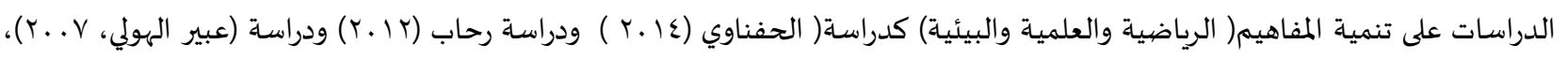

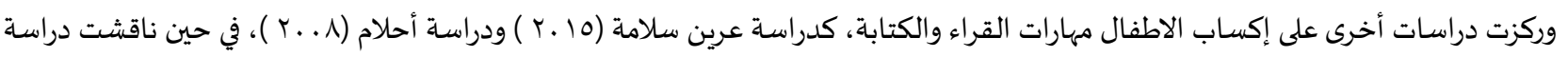

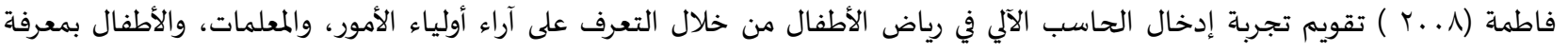

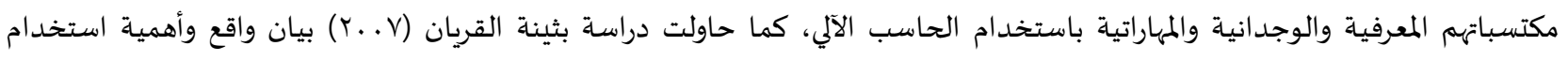




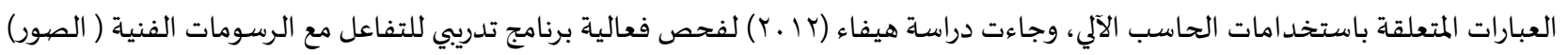

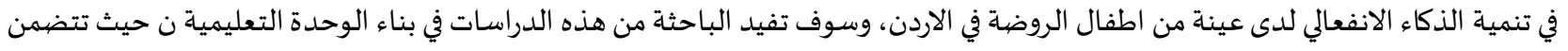

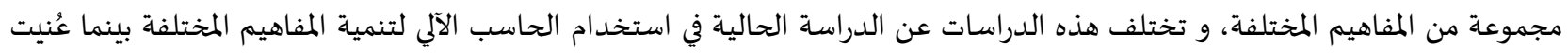

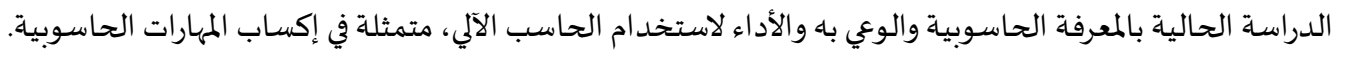

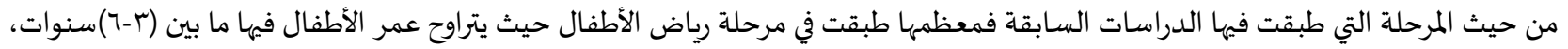

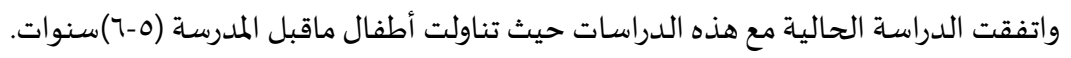

بالنسبة لأدوات الدراسة استخدمت جميع الدراسات برامج حاسوبية ومقاييس أو اختبارات تشمل تنمية المفاهيم المختلفة المذكورة في الدراسة،

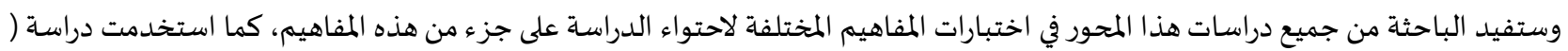

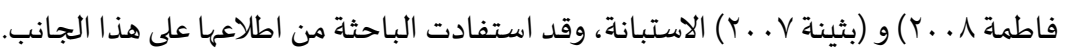

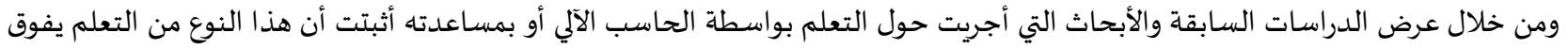

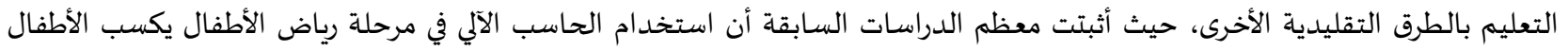

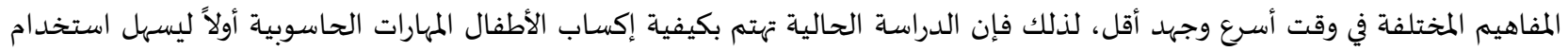

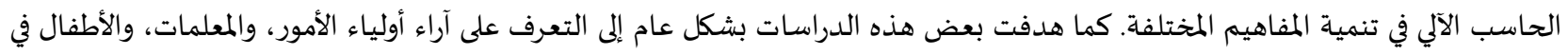
استخدام الحاسب الآلي في مرحلة رياض الأطفال.

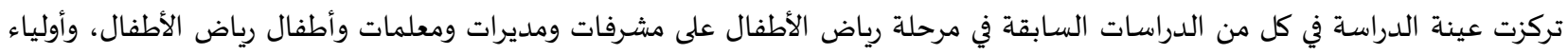

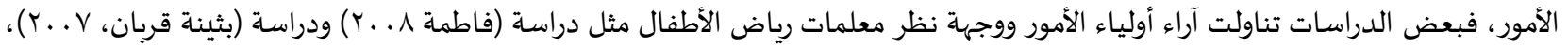

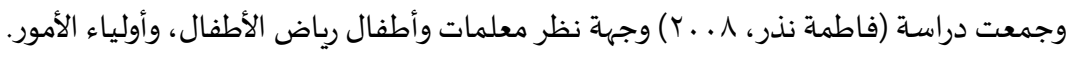

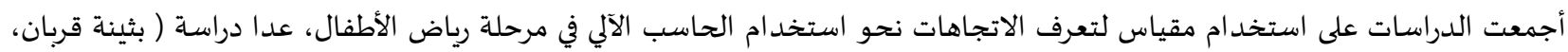

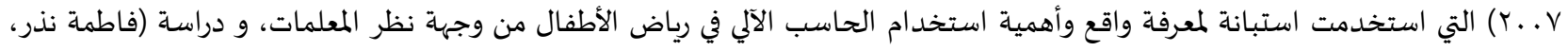

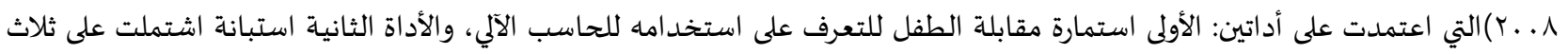

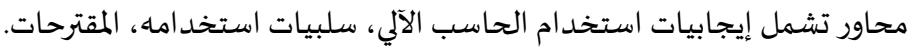

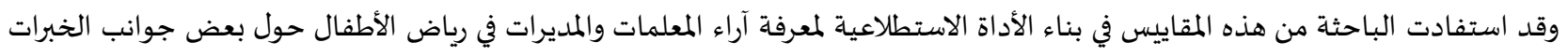
الخاصة بالمهارات الحاسوبية.

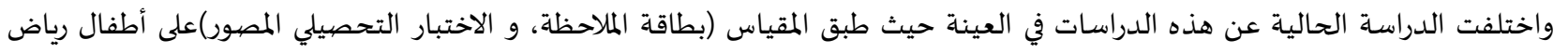

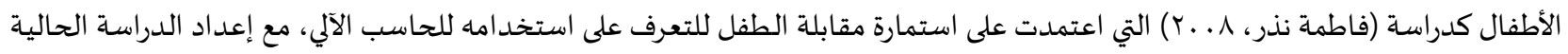

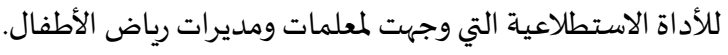

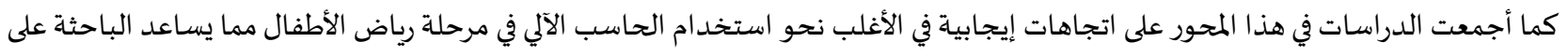
الاطمئنان في تحقيق نتائج أفضل لأدوات الدئ الدراسة.

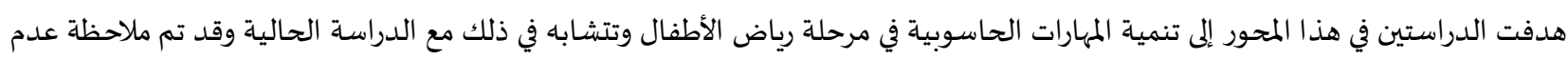
وجود دراسات سابقة عربية - في حدود علم الباحثة - تناولت المهارات الحاسوبية وتنميتها في مرحلة رياض الماض الأطفال.

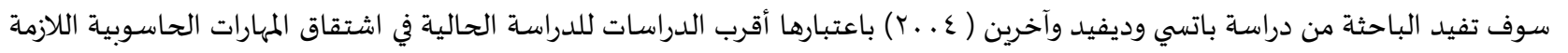

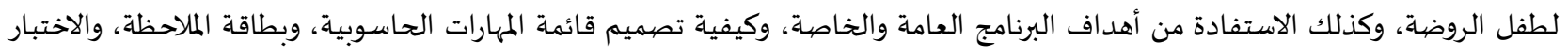

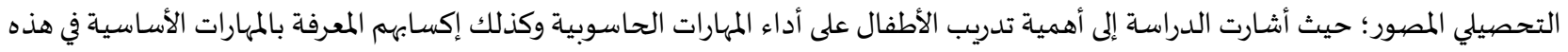

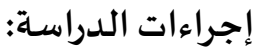

وقد استفادت الباحثة بشكل عام من مراجعة الأدبيات التربوية والتصميمات الإجرائيّة وأهم النتائج التي توصلت إليها الدراسات السابقة، وكانت عوناً لها بعد الله في إعداد هذه الدراسة.

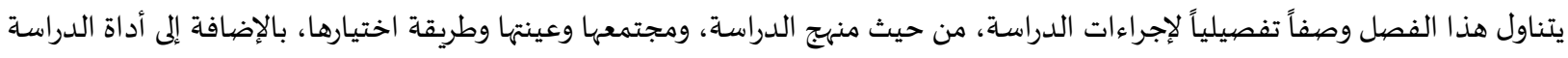

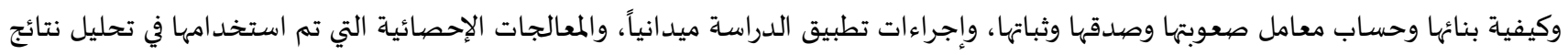
الدراسة. - ماسة 
ولحساب ثبات البطاقة استخدمت الباحثة ثبات المقدارين، فقامت الباحثة مع اثنتين من المدرسات بملاحظة التلاميذ مرة واحدة وقامت الباحثة

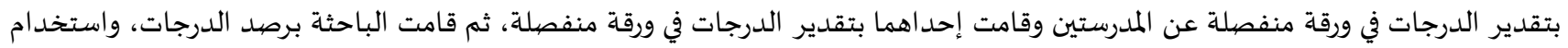

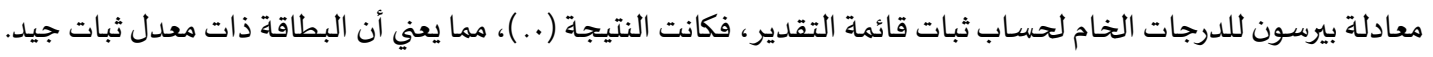
كما تم حساب معامل الثبات لبطاقة الملاحظة باستخدام معادلة كوبر Cooper، فحصلت الباحثة على متوسط نسبة الاتفاق بوء1)، وهي أيضاً نسبة عالية تؤكد موثوقية البطاقة وتمتعها بدرجة عالية من الاتساق الداخلي و صلاحيتها للتطبيق على أطفال تجربة الدراسة.

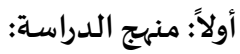

اعتمدت الباحثة المنهج شبه التجريبي Quasi Experimental Design منهجاً لمعالجة مشكلة هذه الدراسة، نظراً لملاءمته لطبيعة المشكلة،

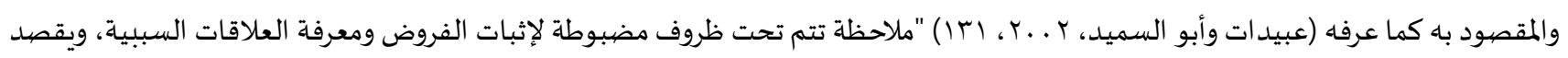
بالظروف المضبوطة إدخال المتغير التجريبي إلى الواقع وضبط تأثير المتغيرات الأخرى. ويعد هذا المنهج في مجال البحوث البهات التربوية والنفسية من أكثر

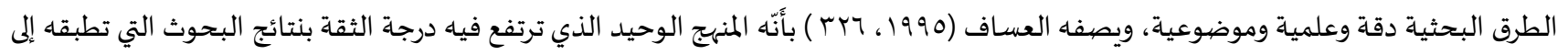

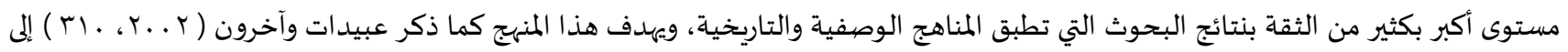

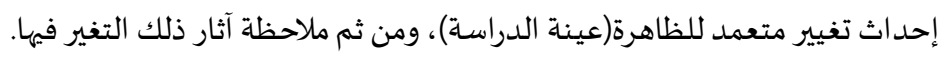

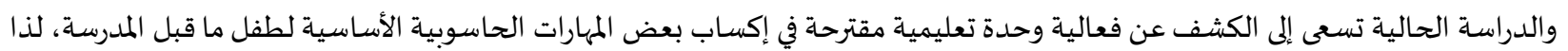

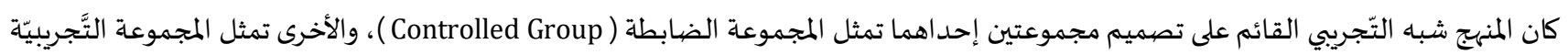
(Experimental Group )

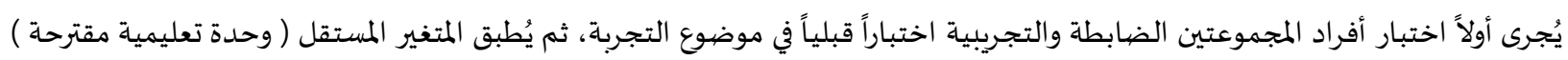

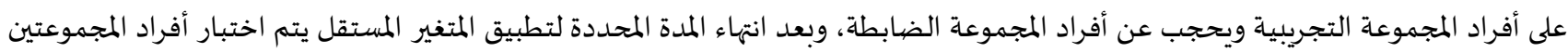

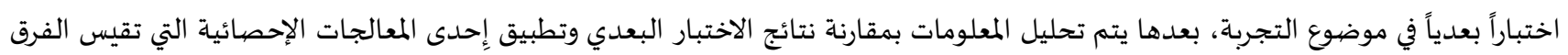

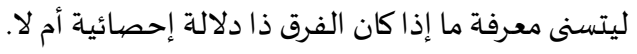
ثانياً: مجتمع الدراسة: معرفة ما إذان

وهو في الدراسات التربوية والنفسية كما ذكر العساف ( 1990 م، ص19 (9) " كل من يمكن أن تعمم عليه نتائج الدراسة "، ويتكون مجتمع الدراسة

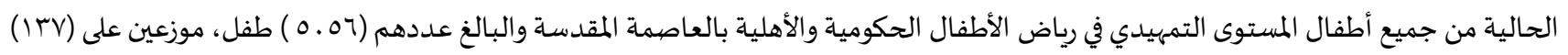

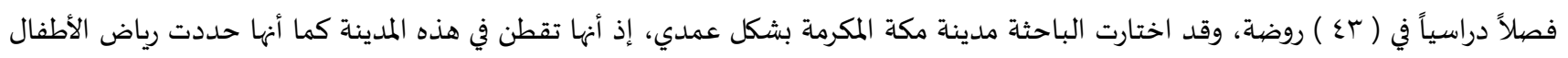

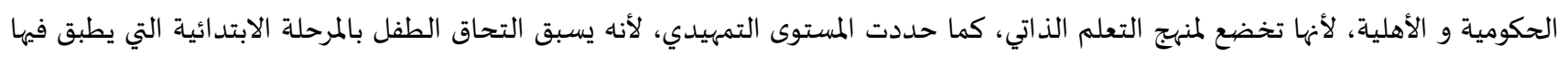

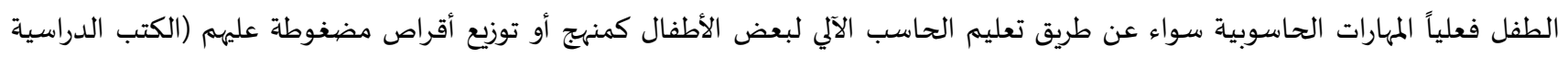
الإلكترونية)، وهو ما يتناسب مع أهداف البحث الحالي. رابعاً: عينة الدراسة:

نظراً لتعذر تطبيق خطوات الدراسة شبه التجريبية على جميع أفراد مجتمع الدراسة لكثرة عددهم فقد اقتصرت الدراسة على عينة تمثل أطفال

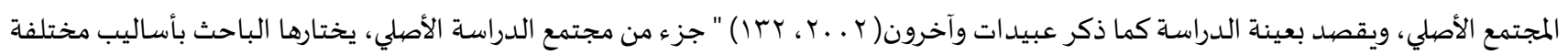

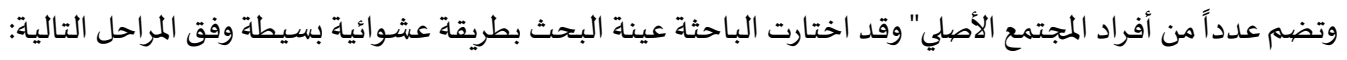
1. . حصر رياض الأطفال بالعاصيمة المقدسة.

r. . تم اختيار روضية بطريقة عشوائية مستخدمة القرعة وقد وقع الاختيار على روضة شعاعة المقاع المعرفة.

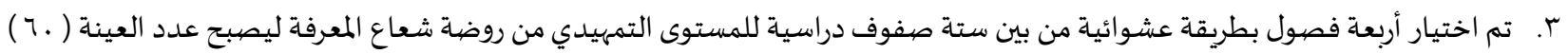
طفلاً. ع. تم اختيار أحد الصفين بطريقة عشوائية ليمثل المجموعة التّجريبيّة، وقد بلغ عددها( .ب ) طفلاً ( 10 اذكور، 10 إناث )، والصف الأخر مثل

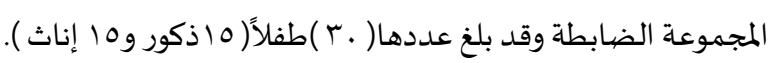

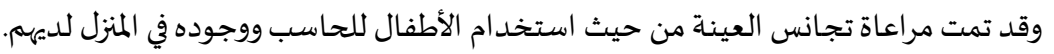
خامساً: أدوات الدراسة: للإجابة عن أسئلة البحث واختبار فروضيه، قامت الباحثة بإعداد الأدوات، بهدف تحديد مستوى الأطفال في المهارات الحاسوبية بعد التعرض للوحدة التعليمية المقدمة، وقد تطلب إعداد الأدوات ما يلي: 
تحديد قائمة المهارات المعرفية والحركية الحاسوبية: تم تحديد القائمة بعد الرجوع إلى المقاييس المرتبطة بالموضوع وإلى الكتب والمراجع التطبيقية للبدء في تعلم المهارات الحاسوبية لطفل ما قبل المدرسة.

قائمة المهارات الحاسوبية المعرفية:

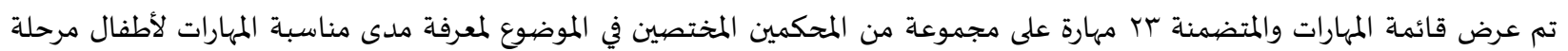

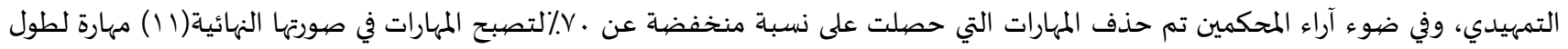

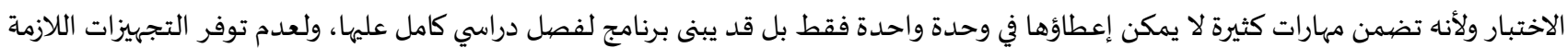

لتطبيق المهارات المتعلقة بالإنترنت. قائمة المهارات الحاسوبية الأدائية:

تم عرض قائمة المهارات والمتضمنة ( 1 ) مهارات أسـاسية و ( ع || ) مهارة فرعية، على مجموعة من المحكمين المختصين في الموضوع، لمعرفة مدى

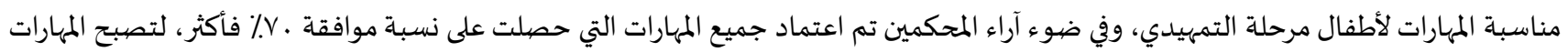

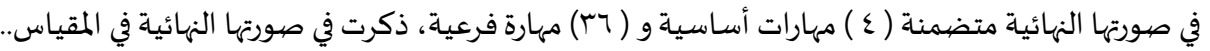

إعداد أدوات الدراسة:

أولاً: الاختبار التحصيلي المصهور:

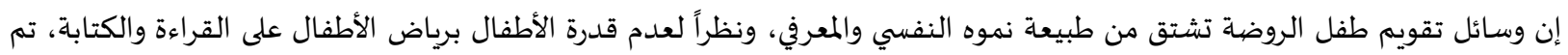

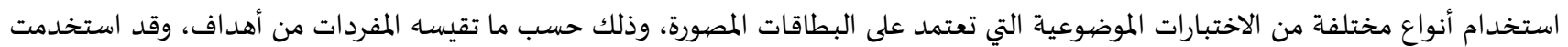

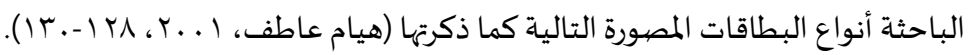

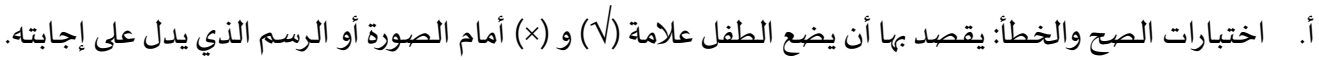

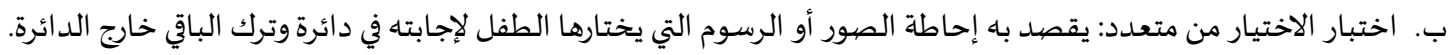

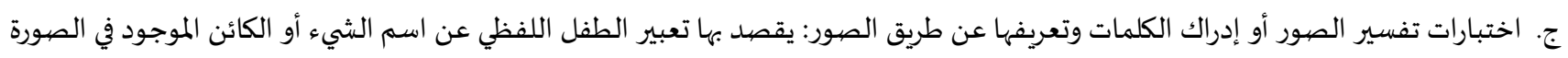

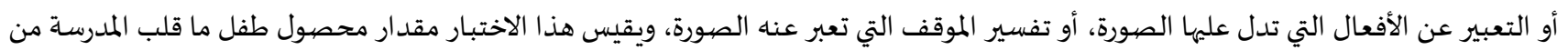

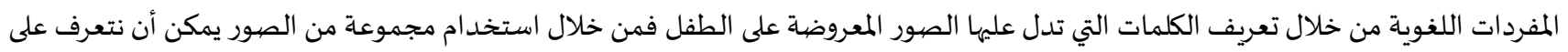

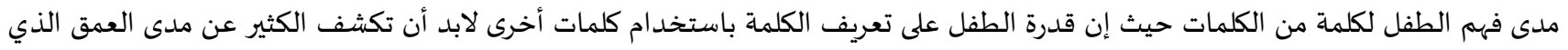

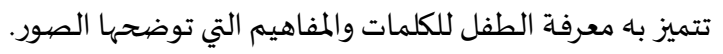
د. اختبارات التصنيف: يقصد بها وضع الطفل دائرة أو علامة معينة يميز بها الأشياء أو الكائنات التي تنتمي إلى مجموعات معينة وفقاً لمعيار حسي تعنيه

هـ اختبارات التسلسل: يقصيد بها إعادة ترتيب صهور تمثل تسلسلاً منطقياً. وقد تم إعداد الاختبار التحصيلي المصيور في صورته الأولية على النحو التالي:

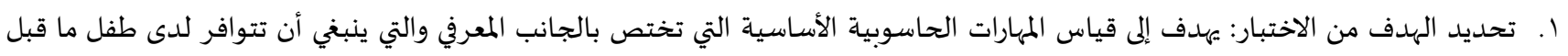
المدرسـة. r. تحديد مفردات الاختبار: تم بناء الاختبار بما يتناسب مع أطفال المرحلة العمرية من (0-7) سنوات، فتنوعت المفردات ما بين شفهية وكتابية، وأخرى عملية تطبيقية لكل مفردة من مفردات الاختبار.

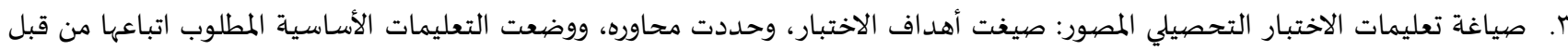

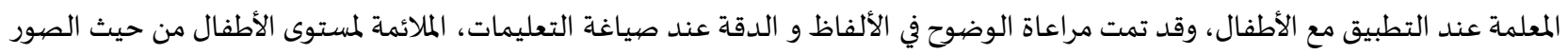

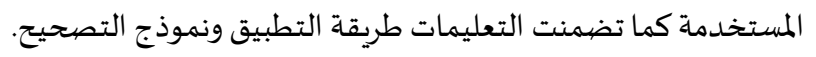
ثانياً: بطاقة الملاحظة:

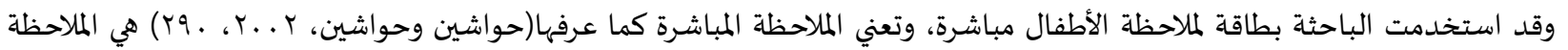

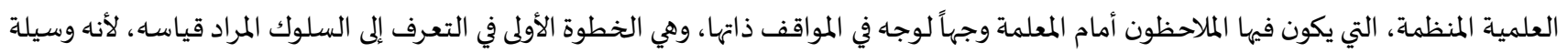

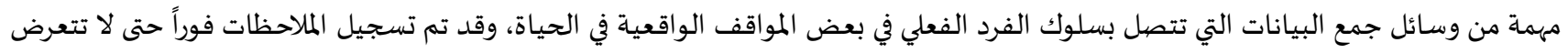
للنسيان، مما يضطر المعلمة اللجوء إلى التخمين، وتمت مراعاة أن تكون محددة ومركزة، وسجلت تاريخ كل ملاحظة ومكانها وزمانها وأسماء من قاموا

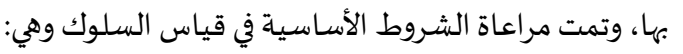




$$
\text { أ. تحديد السلوك الذي سوف يقيسـ الملاحظ بشكل دقيق، مع استبعاد قياس أكثر من سلوك وأحد في الوقت نفسـه. }
$$

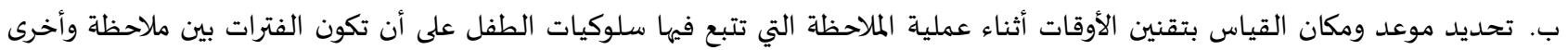

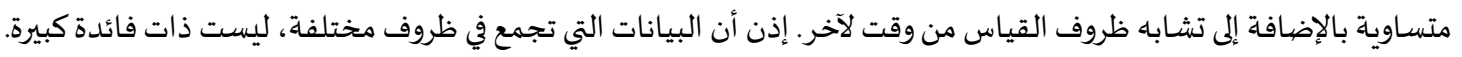

$$
\text { ج. تحديد مدة الملاحظة وهي الفترة الزمنية التي يحدث فيها السلوك المستهدف. }
$$

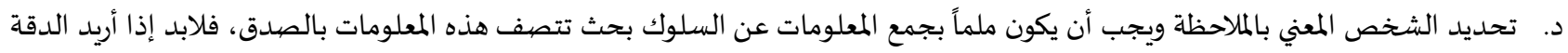
في قياس السلوك المستهدف أن يكون شخصاً على دراية بالسلوك المستهدف وبتعريفه وبصفاته وأخيراً بطرق القياس المستخدمة (حواشين

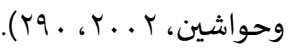

وقد تم إعد اد بطاقة الملاحظة على النحو التالي: ا. تحديد الهدف من بطاقة الملاحظة: تهدف إلى قياس المهارات الحاسوبية الأساسية التي تختص بالجالئانب الأدائي، والتي ينبغي أن تتوافر لدى طفل ما

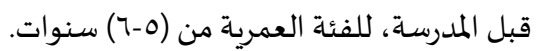
r. الحديد محاور بطاقة الملاحظة: تتكون بطاقة الملاحظة من المحاور التالية وفقاً لمستوى البدء بالأهم، ومن الأسهل إلى الأصعب:

$$
\begin{aligned}
& \text { فتح وإغلاق الحاسب الآلي. } \\
& \text { البدء باستخد ام الفأرة. } \\
& \text { البدء باستخدام لوحة المفاتيح. } \\
& \text { البدء باستخدام الأقراص والبرمجيات الجاهزة. }
\end{aligned}
$$

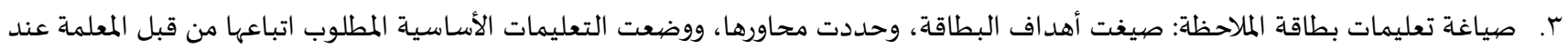

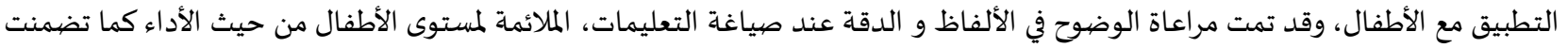
التعليمات طريقة التطبيق ونموذج التصحيح، وقد خصصت الباحثة لكل مفردة درجة واحدة فقط، فأصبح مجموع درجات بطاقة الملاحظة(بساء

$$
\text { صدرق الأدوات: }
$$

يقصد بصدق الاختبار كما عرفه عبيدات وآخرون ( r . . ، Y 19 ) بأنه " قياس الاختبار لما وضع الاختبار من أجله "، وللتحقق من صددق الاختبار

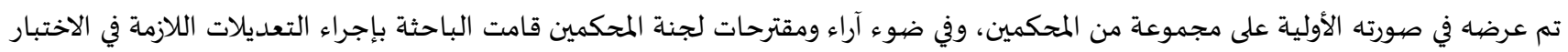
التحصيلي المصور وذلك: تبديل بعض الصور بصور أخرى أوضح. توضيح صياغة بعض الأسئلة.

كما قامت الباحثة بإجراء التعديلات اللازمة في بطاقة الملاحظة وذلك: بحذف الائلة (ع) مهارات أساسية من بطاقة الملاحظة، فأصبح عدد المهارات الأساسية (乏) تتضمن ( רץ) مهارة فرعياة. ثبات الأدوات:

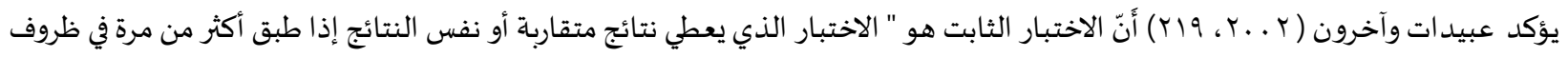
متماثلة ".

وبعد قيام الباحثة بإجراء التعديلات التي اقترحها المحكمون، تم تجربة الأدوات على عينة من أطفال المستوى التمهيدي ( . r طفلاً ) بالروضاة

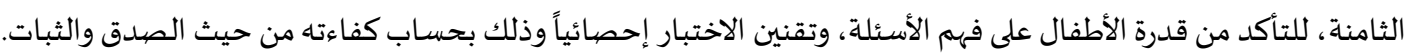
وقد استخدمت الباحثة طريقتين لحساب ثبات الاختبار: ا ـ طريقة الاتساق الداخلي:

يقصد بها مدى اتساق مفردات الاختبار مع بعضها باستخدام معادلة ألفا كرونباخ ( Alpha Cronbach) التي ذكرها ( علام، 0. . r، 170 ) وفقاً للصيغة الرياضية: ن - $=-=\&$ ن حيث: ( ن ) العدد الكلي لأسئلة الاختبار. 
(عجـع ك ) مجموع تباين درجات أسئلة الاختبار. (ع ع ) تباين درجات أسئلة الاختبار.

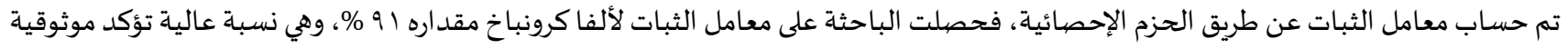
الاختبار وتمتعه بدرجة عالية من الاتساق الداخلي، و صاحلاحيته للتطبيق على أطفال تجربة الدراسـة.

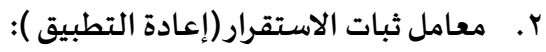

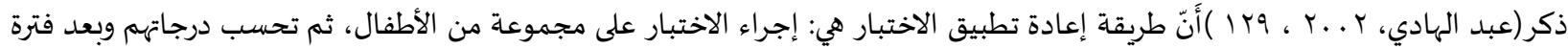

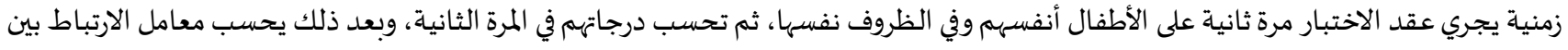

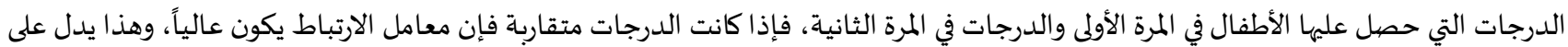
أن الاختبار يمتاز بالثبات.

وقد قامت الباحثة بتطبيق الأدوات على عينة استطلاعية مكونة من ( . r ) طفلاً ثم كررت تطبيق الاختبار على العينة نفسها بعد فترة زمنية

محددة(أسبوع)

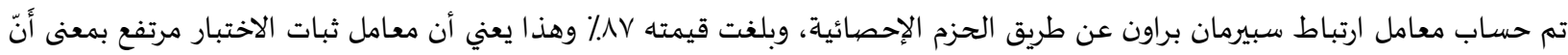

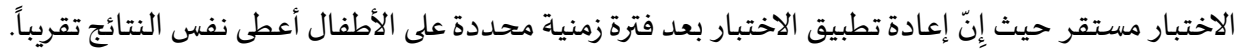

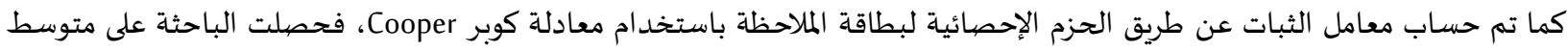
نسبة الاتفاق بو٪٪، وهي أيضاً نسبة عالية تؤكد موثوقية الاختبار وتمتعه بدرجة عالية من الاتساق الداخلي و صلاحيته للتطبيق على أطفال تجربة الدراسـة. ثالثاً: إعداد الوحدة التعليمية المقترحة ( وحدة الحاسب الآلي): تم إعداد الوحدة التعليمية وفقاً للخطوات التالية: 1. الاطلاع على المراجع ذات الصلة بالموضوع المتمثلة فيما يلي: منهج التعلم الذاتي المتمثل في الوحدات التعليمية. ب. البرنامج اليومي في بعض رياض الأطفال بمكة المكرمة. ج. الكتب والدراسات الخاصة بموضيوع الحاسب الآلي. د. برمجيات الحاسب الآلي المتعلقة بالموضيوع.

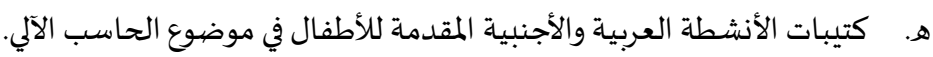
و. المواقع التعليمية على الشبكة العنكبوتية. r ا إعداد الوحدة التعليمية في صورتها الأولية:

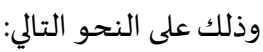

$$
\text { أ. اختيار موضوع وعنوان الوحدة: (وحدة الحاسب الآلي) }
$$

ب. تحديد وتوصيف الخبرة التعليمية في إطارها العام: حيث سيتم التركيز على إكساب المهارات الحاسوبية الأساسية (المعرفية والأدائية) لطفل ما قبل المدرسـة. ج. تحليل المحتوى: تم تحليل المحتوى إلى قواعد، تعميمات، مفاهيم. د. إعداد مرجع الوحدة الذي يحتوي على المفاهيم والخبرات التي ينبني تضمينها في الوحدة، والأهداف العامة والخاصية، وتعليمات المعلمة، و و

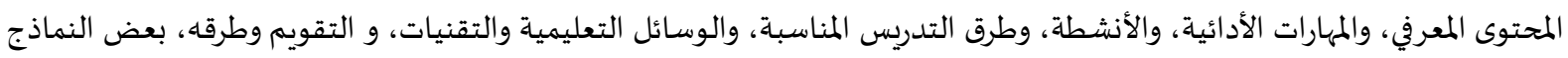
للتمارين، أنشطة ومهارات إضافية، وأخيراً للبدء في تخطيط الوحدة، وهنه و إعلان الأهالي.

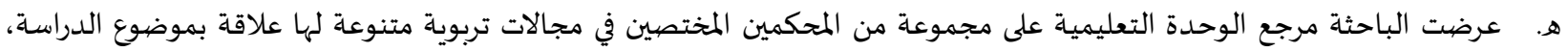
للتحقق من: مناسبة الوحدة التعليمية المقترحة للأطفال في مرحلة رياض الأطفال من حيث (الهدف، المحتوى، طرق التدريس والوسائل التعليمية، التقويم). و. أخذت الباحثة بآراء المحكمين، وتم استبدال بعض الصور بصور أكثر وضوحاً، وتم حذف بعض الأهد اف الفرعية التي لا علاقة لها بموضوع الحاسب الآلي، وتم التركيز على الأهداف الأساسية، وحددت مجالات الأهداف، ومستوياتها، وأصبح مرجع الوحدة في صورته النهائية. 
ز. ثم تم إنتاج الوسائل التعليمية المتعلقة بوحدة الدراسة بمساعدة طالبات مادة إنتاج الوسائل التعليمية، حيث تم شرح الهدف من إنتاج

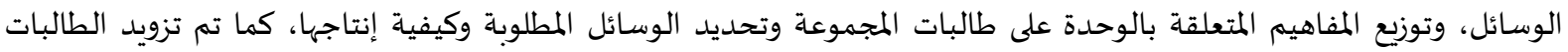

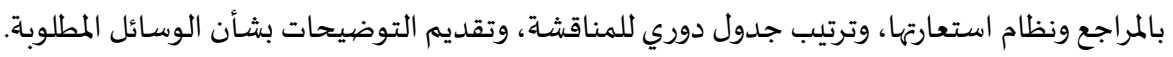

$$
\begin{aligned}
& \text { ح. أعدت الباحثة تخطيط وحدة الحاسب الآلي. } \\
& \text { رابعاً: تطبيق الدراسة ميدانياً: } \\
& \text { تمت الموافقة على تطبيق الدراسة من قبل المشرف، والقسه. }
\end{aligned}
$$

تم الحصول على خطاب سعادة عميدة كلية التربية للأقسام الأدبية، وبناءً عليه تمت موافقة الإدارة العامة للتربية والتعليم بمكة المكرمة(بنات) على تطبيق الدراسة في الفصل الدراسي الثاني في روضية شعاع المعرفة.. تمت زيارة روضاة التطبيق للدراسة ( روضهة شعاع المعرفة )، ومقابلة المديرة، وتسليمها الخطاب الموجها من إدارة التعليم لتسهيل مهمة الباحثة، ووضحت لها الهدف من الدراسة وكيفية تطبيقها. أحضرت الباحثة الوسائل التعليمية والبرمجيات التي ستستخدم في تطبيق الوحدة.

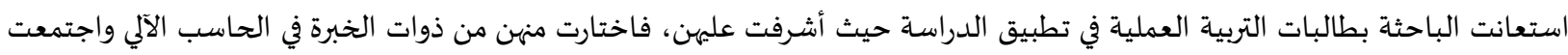

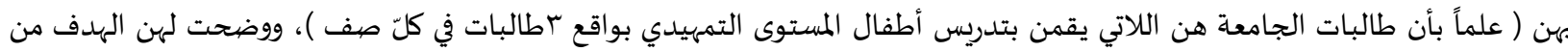

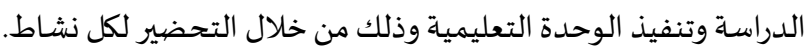
وقد حرصت الباحثة على عدم اطلاع الطالبات المسؤولات عن صف المجتموعة الضابطة على الوحدة المقترحة حتى لا يتأثرن بها. تم إرسال إعلان الوحدة لأسر الأطفال. تم تطبيق استمارة المستوى الاقتصادي والاجتماعي على المجموعة التجريبية والمجموعة الضيابطة لمراعاة التجانس للعينة من حيث المستوى الاقتصادي والاجتماعي حتى لا تؤثر في نتائج البحث.

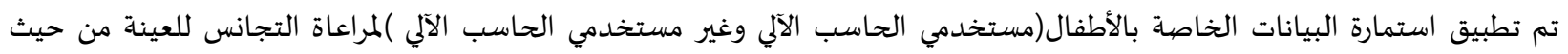

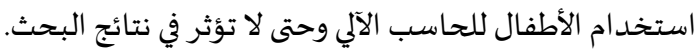
تم تطبيق الأدوات تطبيقاً قبلياً على المجموعة التجريبية والمجموعاة الضيابطة،، وقد استغرق التطبيق أسبوعاً واحداً من خلال جلستين. بدأ تطبيق الوحدة على النحو التالي: المجموعة التجريبية: هي مجموعة الأطفال الذين تعرضوا للمتغير التّجريبي وهو وحدة تعليمية مقترحة موظفة في أنشطة تعليمية هادفة في إكساب المهارات الحاسوبية. المجموعة الضيابطة: هي مجموعة الأطفال الذين لم يتعرضوا للمتغير التّجريبي. قام بتقديم الأنشطة في المجموعة التجريبية والمجموعة الضابطة طالبات التربية العملية بإشراف الباحثة، ومعلمتي الفصل حيث قامت الباحثة

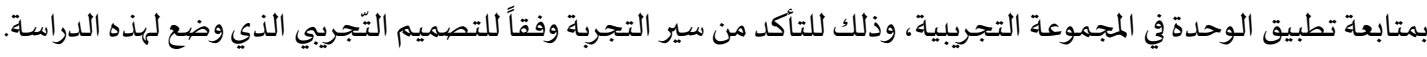
تم الانتهاء من تطبيق الوحدة. بعد الانتهاء من تطبيق الوحدة، تم تطبيق الأدوات تطبيقاً بعدياً على أطفال المجموعتين التجريبية والضابطة، وقد أعطيت الباحثة إفادة من مديرة الروضة بإنهاء تطبيق دراستها كما في. تونئ.

$$
\begin{aligned}
& \text { الأسـاليب الإحصيائية المستخدمة: } \\
& \text { اختبار ت لمجموعتين مستقلتين. }
\end{aligned}
$$

\section{نتائج الدراسة ومناقشتها وتفسيرها:}

يتضمن هذا الفصل عرض وتحليل النتائج التي توصلت إليها الدراسـة، ثم مناقشتها في ضوء نتائج الدراسات السابقة.

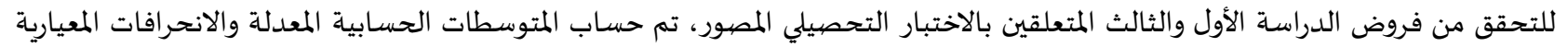
لمجموعتي الدراسة ( التجريبية والضابطة ) في التطبيق البعدي للاختبار التحصيلي المصور ولكل مهارة من المهارات الحاسوبية المحددة، ولمعرفة ما إذا 
كانت الفروق بين متوسطي المجموعتين ( التجرببية والضابطة )في الاختبار البعدي هي فروق ذات دلالة إحصائية، تم إجراء اختبار ت لعينيتين مستقلتين، واختبار مان وتيني للفرق بين الجنسين. مانسين.

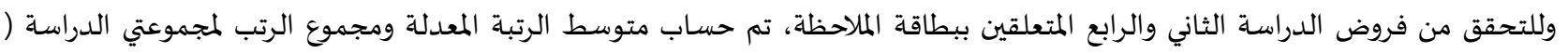
التجريبية والضابطة ) في التطبيق البعدي لبطاقة الملاحظة، ولكل مهارة من المهارات الحاسوبية المحددة، ولمعرفة ما إذا كانت الفروق بين متوسطي

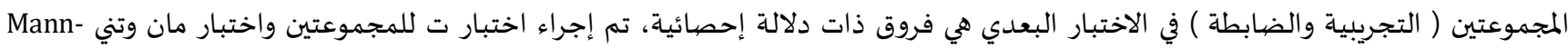

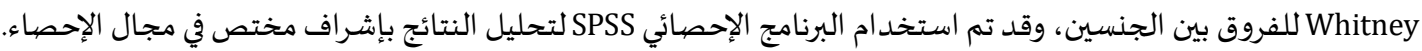
التأكد من تكافؤ المجمموعتين: للتأكد من تكافؤ المجموعتين وتجانسهما وصويلاحيتهما للتطبيق قامت الباحثـة بتطبيق الاختبـار التحصيلي المصيور على مجموعتي الدراسـة وكانت النتائج جدول (1): نتائج اختبارت للتطبيق القبلي للاختبار التحصيل المصهورعلى مجموعتي الدراسة

\begin{tabular}{|c|c|c|c|c|}
\hline مستوى الدلالة & درجات الحرية & قيمة ت & المتوسط & المجموعة \\
\hline \multirow[t]{2}{*}{. AYI } & \multirow[t]{2}{*}{01} & \multirow[t]{2}{*}{. TYA } & 19,70 & الضابطة \\
\hline & & & 19,40 & التجريبية \\
\hline
\end{tabular}

يظهر من الجدول (1) عدم وجود فروق ذات دلالة إحصائية بين متوسطي المجموعتين في الاختبار القبلي مما يؤكد تجانس العينتين وصلاحيتهما للتطبيق عليهما. كما قامت بتطبيق بطاقة الملاحظة قبلياً على المجموعتين، ولإجراء المعالجات الإحصائية تم استخدام اختبار (ت) للعينات المستقلة للتأكد من تكافؤ المجموعتين التجريبية والضابطة في الأداء القبلي و الجدول التالي يوضح القياسات التي تم التوصل لهاء جدول(r): للقياس القبلي للمجموعتين التجريبية والضيابطة في اكتساب المهارات الحاسوبية

\begin{tabular}{|c|c|c|c|c|}
\hline مستوى الدلالة & درجات الحرية & قيمة ت & المتوسط & المجموعة \\
\hline \multirow[t]{2}{*}{. } & \multirow[t]{2}{*}{01} & \multirow[t]{2}{*}{., 119} & 17,50 & الضابطة \\
\hline & & & $17, \mathrm{VA}$ & التجريبية \\
\hline
\end{tabular}

يتضح من الجدول السابق عدم وجود فروق ذات دلالة إحصائية بين المجموعتين التجريبية والضابطة في الأداء القبلي في بطاقة الملاحظة، وبالتالي تكافؤ المجموعتين التجريبية والضيابطة في مهارات استخدام الحاسب الآلي قبل تطبيق الوحدة التعليمية.

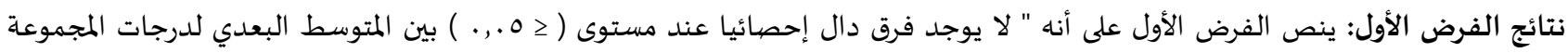
التجريبية (التي درست بالوحدة المقترحة) والمتوسط البعدي لدرجات المجموعة الضابطة (التي لم تدرس بالوحدة المقترحة) في الاختبار التحصيلي المصور في التطبيق البعدي ". ولاختبار صححة الفرض السابق تم حساب المتوسط البعدي لدرجات المجموعة التجريبية والمجموعة الضابطة في الاختبار التحصيلي المصور والجدول التالي يوضح ذلك: جدول (r): قيم المتوسطات الحسابية المعدلة والانحر افات المعيارية لمجموعتي الدراسة (التجريبية والضابطة ) في التطبيق البعدي للاختبار التحصيلي المصهور للمهارات الحاسوبية لمبوعية

\begin{tabular}{|c|c|c|c|c|c|}
\hline \multicolumn{6}{|c|}{ وصف المجموعات } \\
\hline الخطأ المعياري & الانحراف المعياري & المتوسط & العدد ال العد & مجموعات & الاختبار \\
\hline., $\mathrm{V} 0 \leqslant 91$ & $\varepsilon, Y V \cdot V q$ & $r ., r q \varepsilon$ & $r$. & ضابطة & البعدي \\
\hline . & T,VA97Y & $0 \varepsilon, \varepsilon V \Gamma$ & $r$. & تجريبية & \\
\hline
\end{tabular}

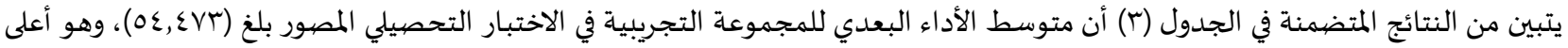
من متوسط الأداء البعدي للمجموعة الضابطة والذي بلغ (ع وr, •r). ولمعرفة دلالة الفرق بين المجموعتين التجريبية و الضيابطة في الاختبار التحصيلي

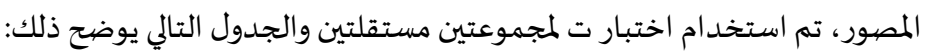


جدول(ع): دلالة الفرق بين المجموعتين التجريبية و الضيطابطة

\begin{tabular}{|c|c|c|c|}
\hline الدلالة & درجات الحرية & قيمة ت & \\
\hline.,$\ldots$ & 01 & $r \varepsilon, V T \varepsilon-$ & الاختبار البعدي \\
\hline
\end{tabular}

يظهر من الجدول السابق وجود فروق دالة إحصائياً عند مستوى ( 0 . ., . ) لصالح المجموعة التجرببية، كما تم حساب مربع إيتا لمعرفة مدى فاعلية الوحدة من الفروق بين متوسطات التطبيقين القبلي والبعدي للمجموعة التجربية وكلما اقترب مربع إيتا من الواحد الصحيح إديح دل ذلك على التأثير الكبير للوحدة.

\begin{tabular}{|c|c|}
\hline مربع إيتا & معامل إيتا \\
\hline ., १६। &., $9 \vee$. \\
\hline
\end{tabular}

والنتيجة السابقة التي تم التوصل إلهها تتفق مع النتائج التي توصلت إلهها دراسة باتسي وديفيد وآخرين ( ع . .بم ). ودراسة (عمرو 10 ــץ) التي

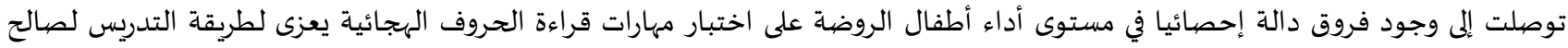
الطريقة المحوسبة، والتي أوصت في ضوء النتائج بضرورة بناء برنامج تعليمي لرياض الأطفال اعتماداً على منهاج رياض الأطفال التفاعلي، موظفاً

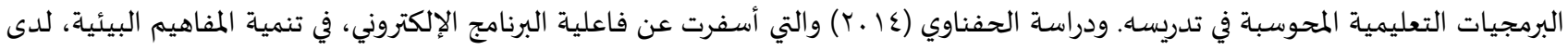

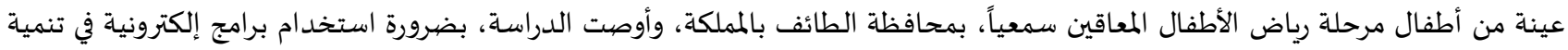

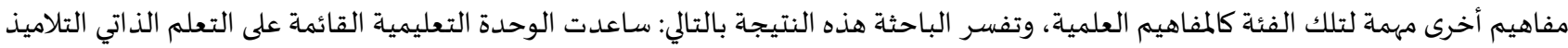

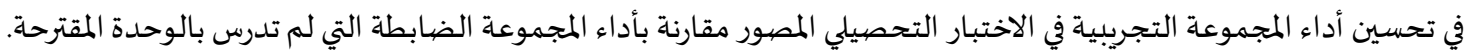

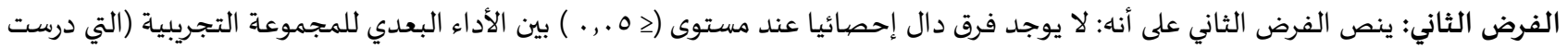

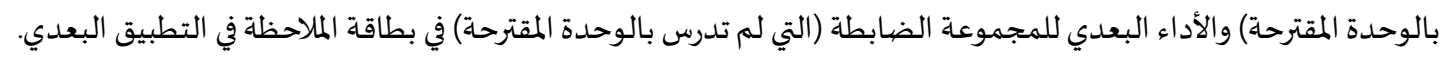
ولاختبار الفرض الصفري السابق تم استخدام اختبار ت للعينات المستقلة للتأكد من دلالة الفروق بين المجموعتين التجريبية والضابطة في الأداء

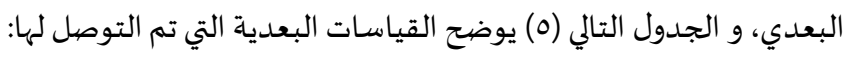

جدول(0): نتائج اختبارت للقياس البعدي للمجموعتين التجريبية والضابطة في اكتساب المهارات الحاسوبية

\begin{tabular}{|c|c|c|c|c|c|}
\hline \multicolumn{6}{|c|}{ وصف المجموعات } \\
\hline الخطأ المعياري & الانحراف المعياري & المتوسط & العدد & مجموعات & بطاقة الملاحظة \\
\hline . & $r, \wedge q \vee$ & 99.17 & $r$. & ضابطة & البعدي \\
\hline . ITI & $r, I T \varepsilon$ & $\{0 . \pi 1$ & $r$. & تجرببية & \\
\hline
\end{tabular}

يتضح من الجدول السابق وجود فروق ظاهرية بين متوسطي المجموعة التجريبية والمجموعة الضابطة، ولمعرفة اتجاه هذه الفروق ودلالتها تم

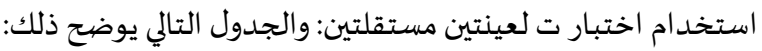

جدول(7): دلالة الفرق بين المجموعتين التجريبية و الضابطة

\begin{tabular}{|c|c|c|c|}
\hline الدلالة & درجات الحرية & قيمة ت & \\
\hline.,$\ldots$ & 01 & $1 \varepsilon .{ }_{1}$ & لاختبار البعدي \\
\hline
\end{tabular}

يظهر من الجدول السابق أن قيمة (ت) بلغت( KN. ع ()، وهي قيمة دالة إحصائيا عند ( .. 0.) مما يدل على رفض الفرض الصفري السابق وقبول الفرض البديل والذي ينص على أنه "يوجد فرق دال إحصائيا عند مستوى (20. . . . )، بين الأداء البعدي للمجموعة التجريبية ( التي درست

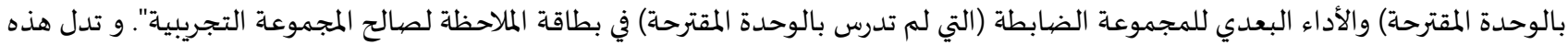

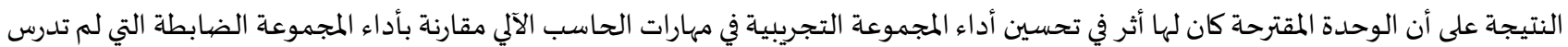

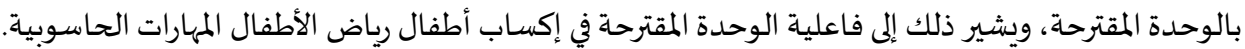

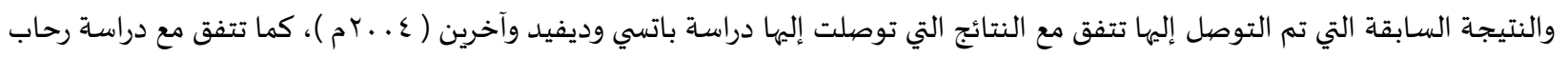

(Y. IT) (Y. T) وهيفاء)

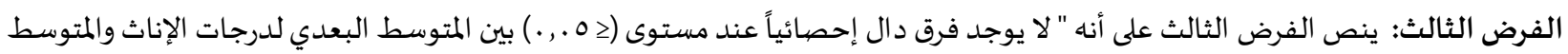

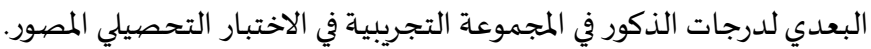


ولاختبار الفرض الصفري السابق تم استخدام اختبار استخدام اختبار (مان وتني) للعينات المستقلة و الجدول التالي يوضح القياسات البعدية

التي تم التوصل لها:

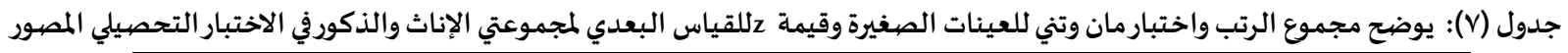

\begin{tabular}{|c|c|c|c|c|c|c|}
\hline الدلالة & $\mathrm{z}$ & Mann-Whitney & مجموع الرتب & متوسط الرتبة & العدد & المجموعة \\
\hline \multirow[t]{2}{*}{ זTו, } & \multirow[t]{2}{*}{., 01} & \multirow[t]{2}{*}{$q \vee, .}$. & $019, .$. & ro.00 & 10 & الإناث \\
\hline & & & $0 \mid v, .$. & rT.O\& & 10 & الذكور \\
\hline
\end{tabular}

يتضح من الجدول السابق أن قيمة مجموع الرتب لدرجات أفراد مجموعة الإناث قد بلغ (. . (0)م)، وهو قيمة أعلى من مجموع الرتب لدرجات

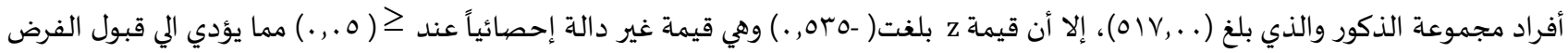

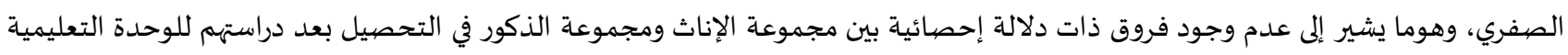
المقترحة.

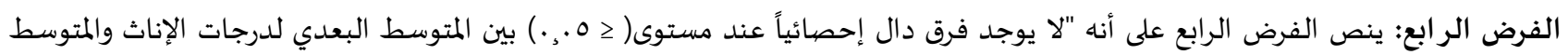

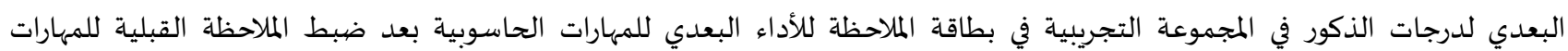

الحاسوبية". ولاختبار الفرض الصفري السابق، تم استخدام اختبار استخدام اختبار مان وتني للعينات المستقلة و الجدول التالي يوضيح القياسات البعدية التي تم التوصل لها:

جدول (^): يوضح مجموع الرتب واختبار مان وتني للعينات الصغيرة وقيمة zللقياس البعدي لمجموعتي الإناث والذكورفي أداء المهارات الحاسوبية

\begin{tabular}{|c|c|c|c|c|c|c|}
\hline الدلالة & z & $\begin{array}{l}\text { Mann- } \\
\text { Whitney }\end{array}$ & مجموع الرتب & متوسط الرتبة & العدد & المجموعة \\
\hline \multirow[t]{2}{*}{., or9 } & \multirow[t]{2}{*}{., Tov- } & \multirow[t]{2}{*}{$9 \mathrm{~V}, .}$. & $T \xi \lambda,$. & $17,0 \mathrm{rr}$ & 10 & الإناث \\
\hline & & & $r \mid \gamma, .$. & $1 \varepsilon, \xi \gamma$ & 10 & الذكور \\
\hline
\end{tabular}

يتضح من الجدول السابق أن قيمة مجموع الرتب لدرجات أفراد مجموعة الإناث قد بلغ ( . . (Y乏))، وهو قيمة أعلى من مجموع الرتب لدرجات

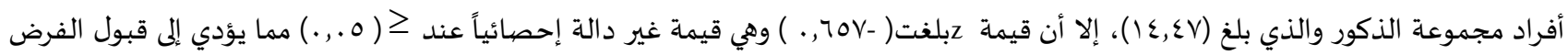

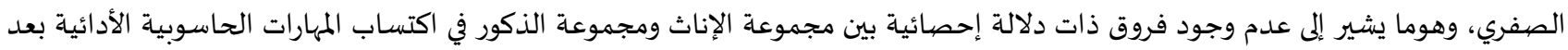

دراستهم للوحدة التعليمية المقترحة.

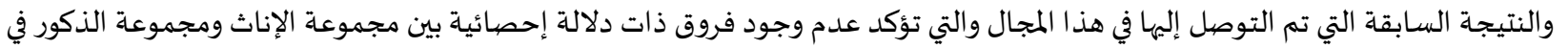

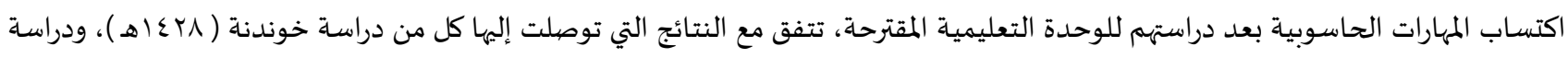

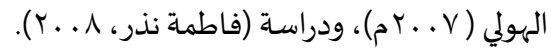
التوصيات والمقترحات:

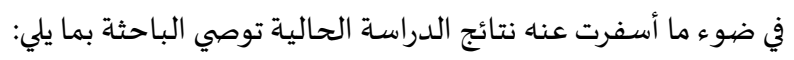

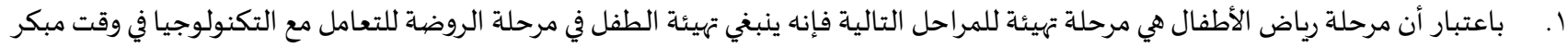

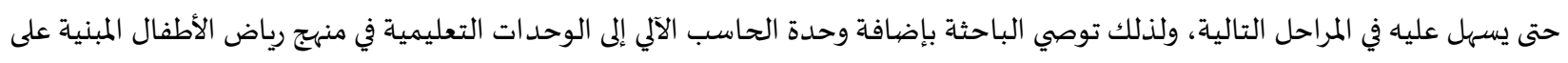
التعلم الذاتي. r. تقديم الوحدات التعليمية في رياض الأطفال على الأقراص المضغوطة مع عدم إغفال تقديمها عن طريق الأنشطة واستخدام الحواس، تماشياً مع استراتيجية التعليم الإلكتروني في المراحل التعليمية التالية.

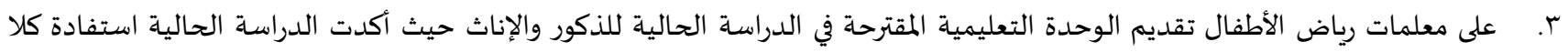

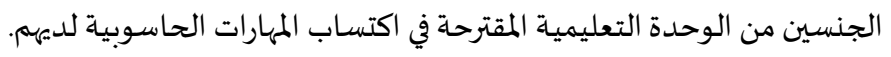
ع. توفير الاحتياجات المادية والمكانية لتفعيل الحاسب الآلي في رياض الأطفال بصورة علمية مقننة حتى تكون له انعكاساته الجيدة على العملية التربوية. 
0. تطوير الخطة الدراسية لقسم رياض الأطفال بجامعة أم القرى بإضافة مقرر دمج التكنولوجيا في أنشطة رياض الأطفال يوضح أهمية التكنولوجيا في مرحلة رياض الأطفال لطالبات قسم رياض الأطفال.

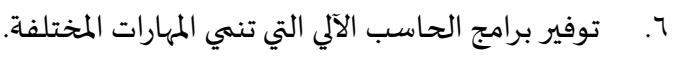

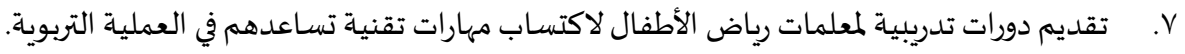

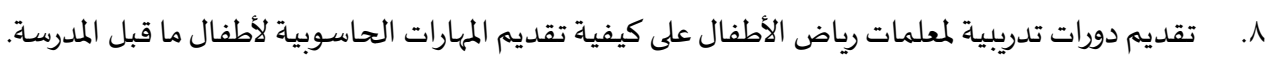

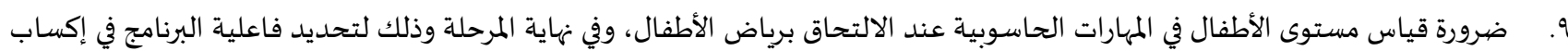
المهارات الحاسوبية. • ا. إعداد دليل إرشادي لأسر الأطفال يوضيح إكساب المهارات الحاسوبية وتوظيفها في المنزل للأطفال.

التوصيات بدراسات مستقبلية:

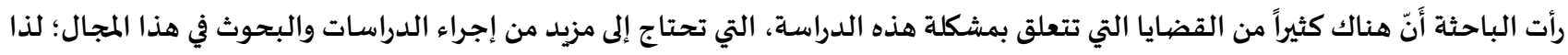
يمكن تقديم بعضها كما يلي:

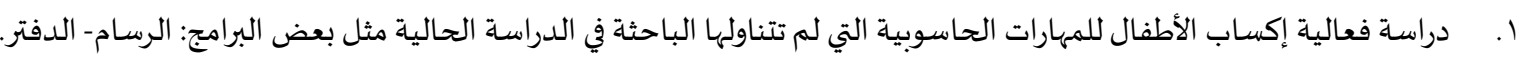

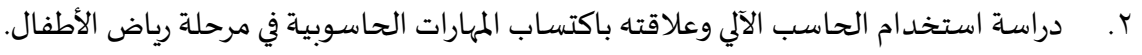

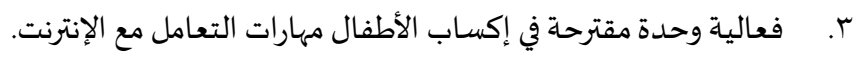

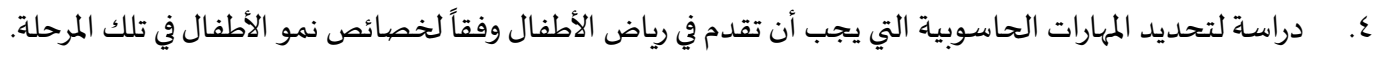
1. دراسة واقع دمج التكنولوجيا في أنشطة رياض الأطفال.

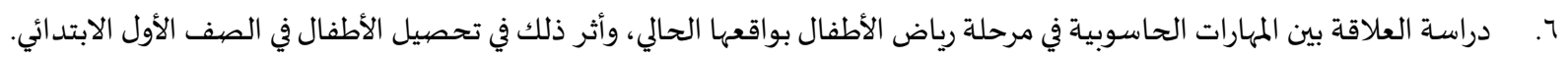

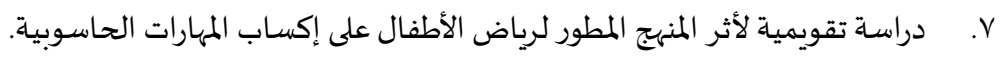

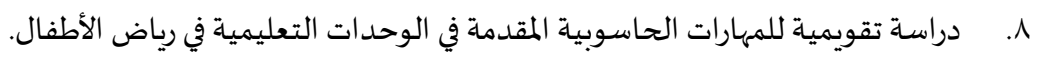

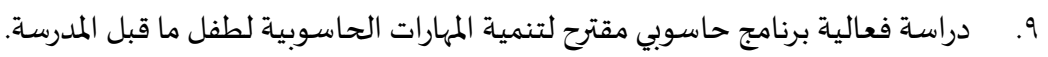

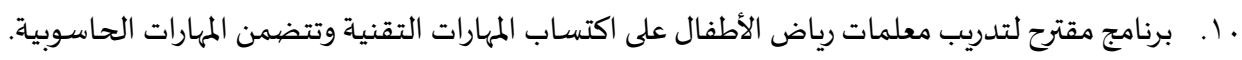

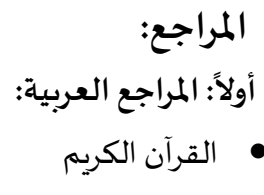

إبراهيم، عبداللطيف. (. 199). المناهج أسسها وتنظيماتها وتقويم أثرها. القاهرة، مكتبة مصري، القاهرة.

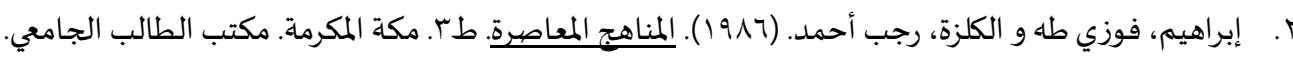

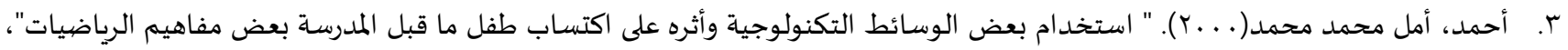

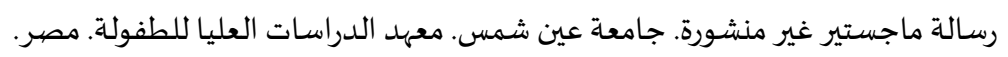

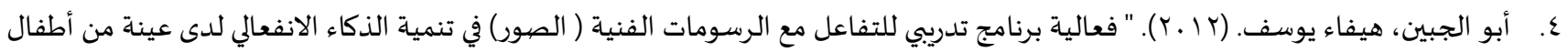

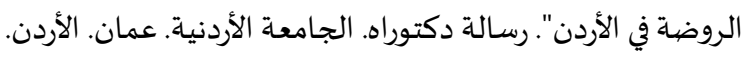

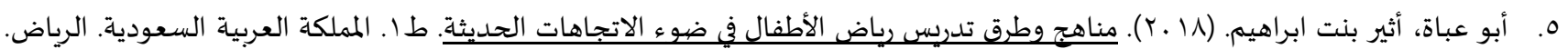
مكتبة الرشد.

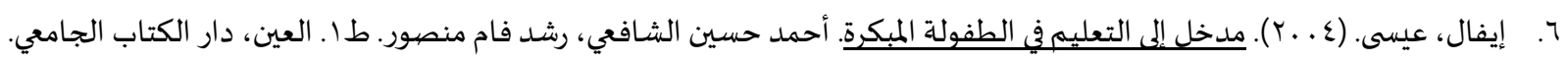

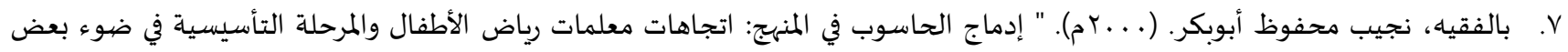

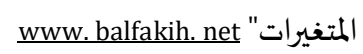
ᄉ. بدير، كريمان محمد. (1 .ب). "الاستعداد للقراءة لطفل الروضة في ضوء استخدام الحاسوب والخبرات المباشرة (الرحلات)"، مجلة القراءة

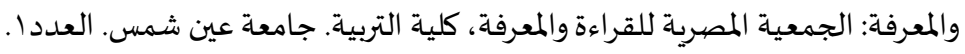

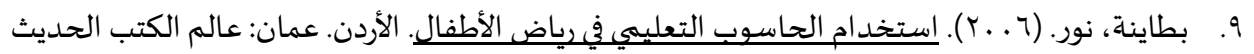

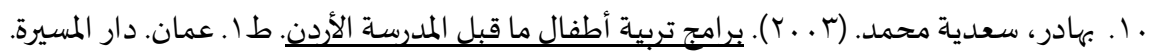

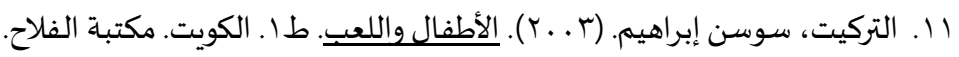




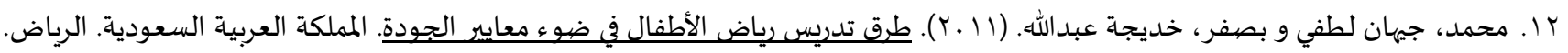
مكتبة الرشـد.

rا . الحراحشة، محممد عبود. (0. . ب). "فاعلية البرامج التدريبية للمعلمين في مديريات التربية والتعليم في محافظة إبربد من وجهة نظر المتدربين". مجلة القراءة والمعرفة: الجمعية المصرية للقراءة والمعرفة. كلية التربية. جامعة عين شمس. العدد ب عـ.

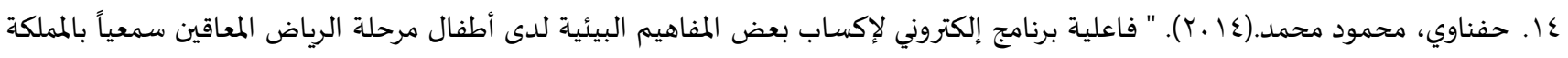

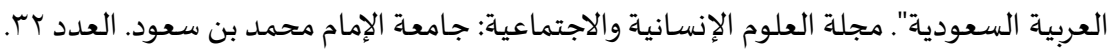

0 ا. حماد، خليل عبدالفتاح و فورة، ناهض صببحي. (ع . . ا). " دور التكنولوجيا في تنمية الاستعداد القرائي لدى رياض الأطفال في محافظات غزة " المؤتمر العلمي الرابع ( القراءة وتنمية التفكير)، القاهرة: الجمعية المصبرية للقراءة واءة والمعرفة.

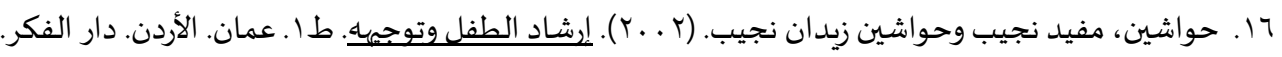

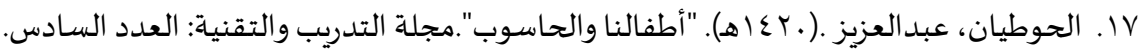

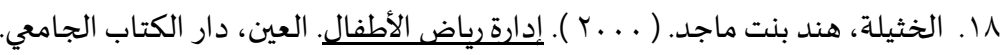

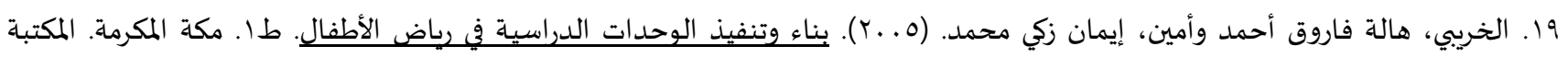
الفيصلية.

•r. الخولي، محمد علي. (ع 1991). قاموس التربية. طَ. لبنان. بيروت. دار العلم للملايين.

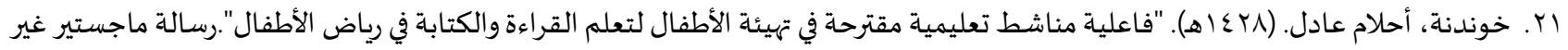
منشورة. كلية التربية. جامعة أم القرى.

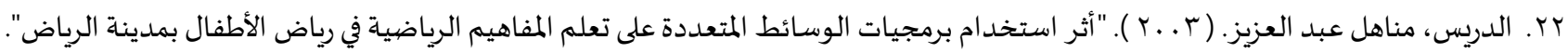
رسالة ماجستير غير منشورة. كلية التربية. جامعة الملك سعود.

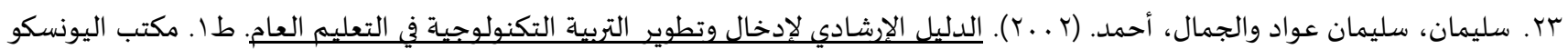
الإقليمي للتربية في الدول العربية. بيروت.

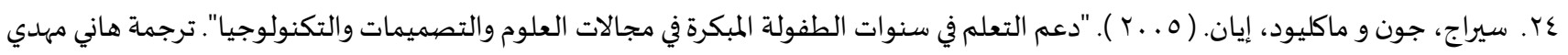
الجمل. القاهرة. مجموعة النيل العربية. ه . سيراج، جون و وايتبريد، ديفيد. (7 . . ب). "تنمية مهارات تكنولوجيا المعلومات والاتصالات في سنوات الطفولة المبكرة "ترجمة بهاء شاهين. القاهرة. مجموعة النيل العربية.

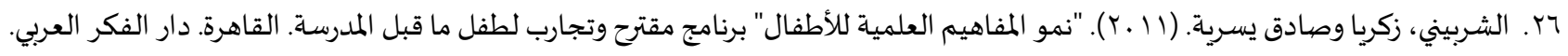

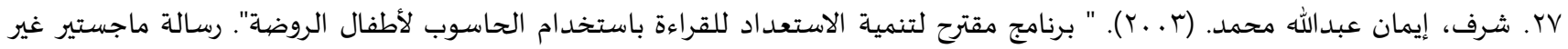
منشورة. جامعة عين شمس. القاهرة.

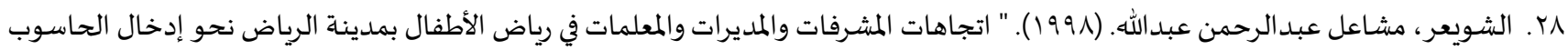

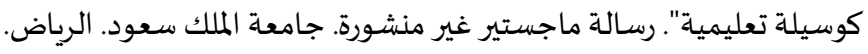

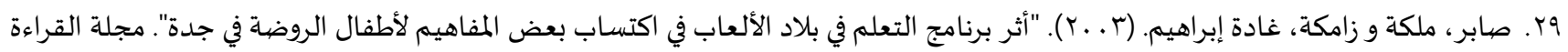

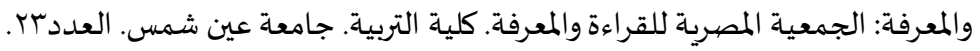

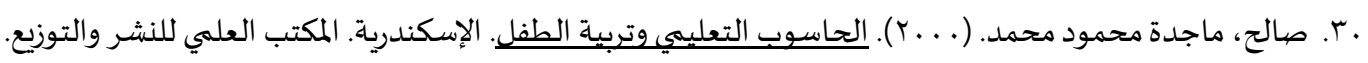

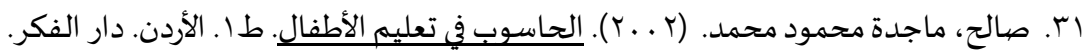

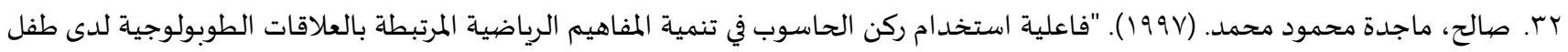

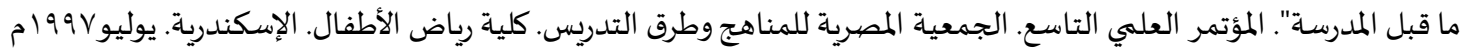

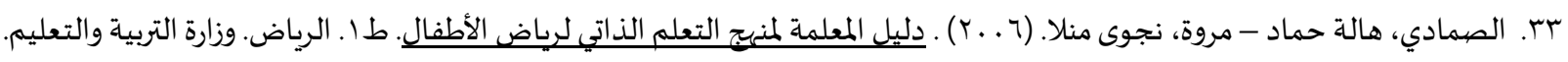

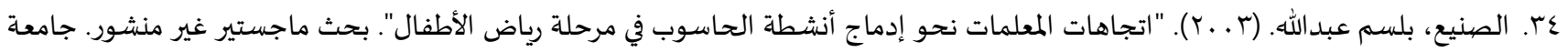

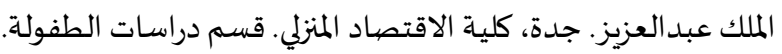
هب. الطوبجي، حسين حمدي. (7 99 (1). "التربية والحاسوب رؤية وواقع". اليونسكو، المنظمة العربية المبية للتربية والثقافة والعلوم، إدارة التقنيات التربوية.

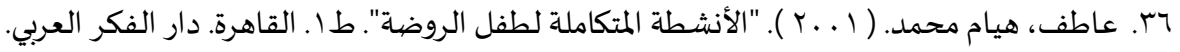

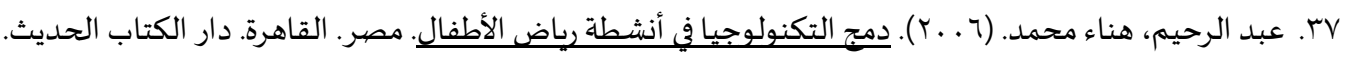




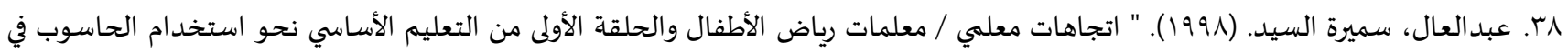

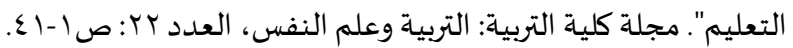

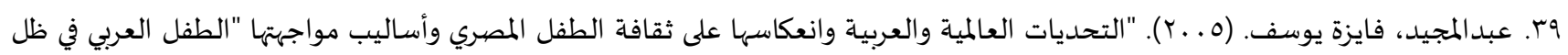

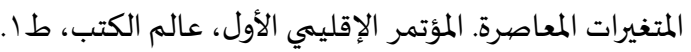

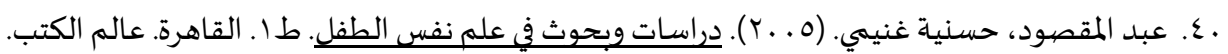

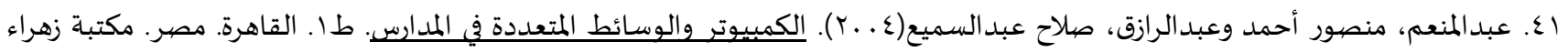
الشرق.

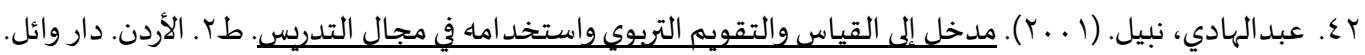

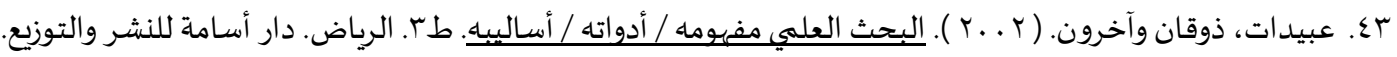

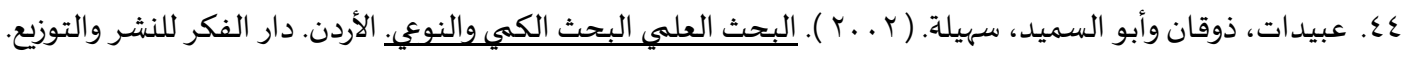

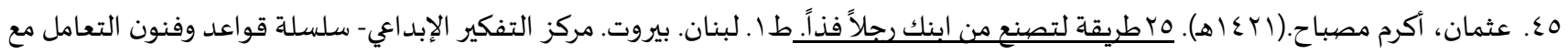
الأبناء. دار ابن حزم.

7 حـ. عدلي، نهى. (0. . †). "كتابي الإلكتروني والمطبوع ". مؤتمر الطفل العربي في مهب التأثيرات الثقافية المختلفة، المجلس العربي للطفولة والتنمية.

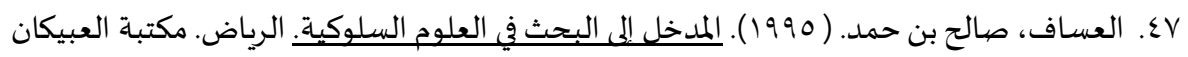

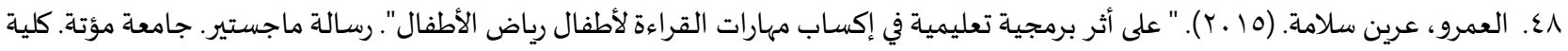
العلوم التربوية. الأردن.

9. علا، لاح الدين. ( . . با. " الأساليب الإحصائية الاستدلالية في تحليل بيانات البحوث النفسية والتربوية والاجتماعية ( البارا مترية واللابارامترية )". القاهرة. دار الفكر العربي. . 0.

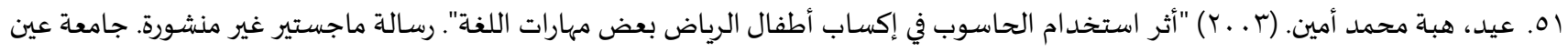
شمس. معهد الدراسات العليا للطفولة.

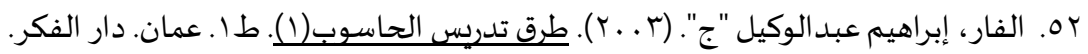

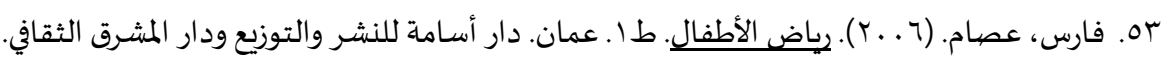

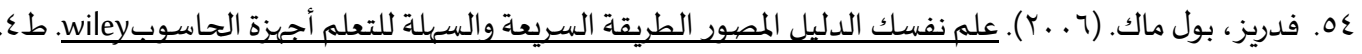
00. فزازي، عبدالسلام. (ع . .ب). " الطفل والشبكة العنكبوتية (الإنترنت)". مجلة الطفولة العربية: الجمعية الكويتية لتقدم الطفولة العبربية. العدد. . إ: .11. 7. قاسم، رانيا محمد علي. (. . . ب). "استخدام الحاسوب وعلاقته بالتفاعل الاجتماعي لدى الأطفال في مرحلة ما قبل المدرسة". رسالة ماجستير غير منشورة. جامعة عين شمس. معهد الدراسات العليا للطفولة.

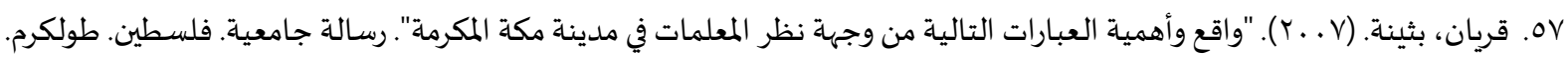

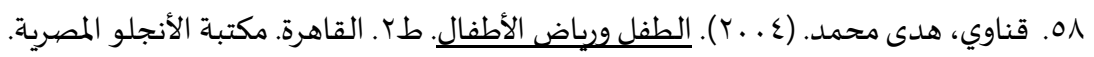

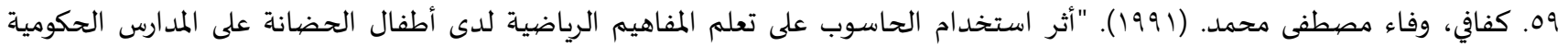
والخاصة". رسالة دكتوراه غير منشورة. معهد البحوث والدراسات التربوية. جامعة القاهرة. •7. مارياد، شريدان، محمد طالب السيد سليمان. (0. . ب). اللعب في الطفولة المبكرة من الميلاد وحتى سن السادسة. غزة ـ فلسطين. دار الكتاب الجامعي. ا7. مازن، حسام محمد.(7 . .ب). "تكنولوجيا المعلومات ووسائطها الإلكترونية"، ورقة عمل بعنوان الحاجة إلى برامج في الثقافة العلمية الإلكترونية لنشر الوعي العلمي نحو التكنولوجيا للطفل العربي. مكتبة النهضية المصرية، القاهرة.

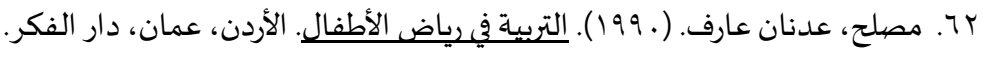

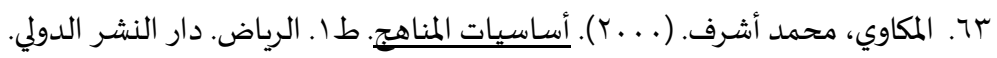

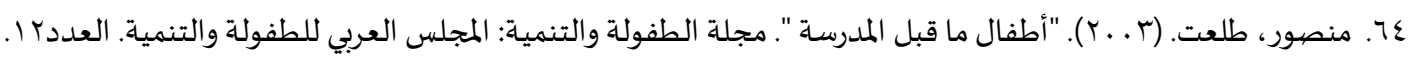
70. نائف، رحاب خلف.(Y ا ـ Y). " تعليم أطفال الروضاة بعض المفاهيم العلمية عن طريق الكمبيوتر". مجلة البحث العلمي في التربية. جامعة عين 
77. الناشف، هدى. (199V). رياض الأطفال. مصر. دار الفكر العربي.

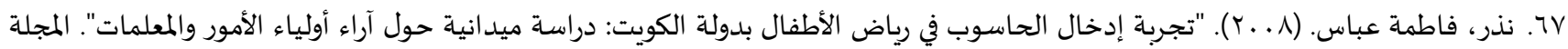

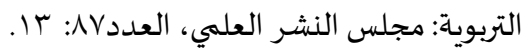

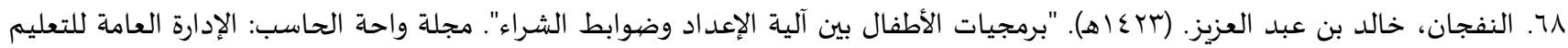
بالرياض. العدد 19:119.

79. الهولي، عبير عبدالله. (V . . r). "أثر استخدام ركن تعليمي مستحدث في تنمية المفاهيم والمهارات والعلاقات الرياضية لدى أطفال الرياض بدولة

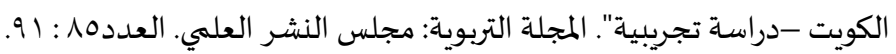

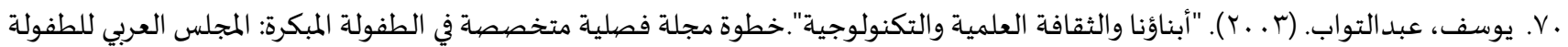
والتنميةة، العددץr.

ثانياً: المراجع الأجنبية:

[1] Sun - Young Kim, (2003), "The Relationship between Kindergarten Teachers General Attitudes Toward Computers ،Self Perceived Computer Competence, and Attitude Toward using Computers in Early Childhood Education." Muonji University ،Korea.

[2] Vergara Hernando, (1995), "Design Development and Implementation of an Instructional Program for To Increase Their Basic Computer Skills through word Processing Training". 107 pp .Dissertations/Theses- Practicum Papers; Tests/Questionnaires Full Text from ERIC Available online from January 1993 onward ; otherwise produced only in microfiche RIEFEB 19961996 ED387239) WWW. ERIC. COM. 


\title{
Examine the effectiveness of a proposed educational unit in providing some basic computer skills for preschool children
}

\author{
Maimoona M. M. H. Abdultawab \\ Umm Al-Qura University, KSA \\ maabdultawab@uqu.edu.sa
}

Received Date : $2 / 1 / 2020$

Accepted Date : $12 / 2 / 2020$

DOI : https://doi.org/DOI:10.31559/EPS2020.8.2.4

Abstract: The aim of the current study is to examine the effectiveness of a proposed educational unit in providing some basic computer skills for preschool children. The researcher followed the quasi-experimental approach based on the design of two groups ،one of which represents the control group and the other represents the experimental group with pre and post testing. The researcher also adopted the sample selection based on the simple random method which consisted of (60) children and girls from the introductory level in the Ray of Knowledge Kindergarten in the Holy Capital. The study sample was divided into experimental groups of (30) children and a control group of (30) children

The study aimed to reveal the effectiveness of a proposed educational unit in providing some basic computer skills in the cognitive and performance domain for preschool children and to discover whether there are differences between male and female members of the experimental group in computer skills in the cognitive and performance domains. The study found that a statistically significant difference between the experimental group and the control group in the achievement test and in the observation card after adjusting the pretest tools in favor of the experimental group. It also found that there is no statistically significant difference between the female and male members of the experimental group in the achievement test and the observation card in computer skills after their study of the proposed unit. The study recommended in the light of the current results adding the computer unit to the educational units in kindergarten and the provision of such educational units in kindergarten and the following educational stages on CDROM as outlined in the e-learning strategy.

Keywords: Skills; Computer; Child; preschool; educational unit.

\section{References:}

- $\quad$ Alqran Alkrym

[1] 'atf, Hyam Mhmd. ( 2001 ). "Alanshth Almtkamlh Ltfl Alrwdh". T1. Alqahrh. Dar Alfkr Al'rby.

[2] Abw 'bah, Athyr Bnt Abrahym. (2018). Mnahj Wtrq Tdrys Ryad Alatfal Fy Dw' Alatjahat Alhdythh. T1. Almmlkh Al'rbyh Als'wdyh. Alryad. Mktbt Alrshd.

[3] 'bd Alrhym, Hna' Mhmd. (2006). Dmj Altknwlwjya Fy Anshth Ryad Alatfal. Msr. Alqahrh. Dar Alktab Alhdyth.

[4] 'bdal'al, Smyrh Alsyd. (1998). " Atjahat M'lmy / M'lmat Ryad Alatfal Walhlqh Alawla Mn Alt'lym Alasasy Nhw Astkhdam Alhaswb Fy Alt'lym". Mjlt Klyt Altrbyh: Altrbyh W'lm Alnfs, Al'dd 22: S1-41.

[5] 'bdalmjyd, Fayzh Ywsf. (2005). "Althdyat Al'almyh Wal'rbyh Wan'kasha 'la Thqafh Altfl Almsry Wasalyb Mwajhtha "Altfl Al'rby Fy Zl Almtghyrat Alm'asrh. Alm'tmr Aleqlymy Alawl, 'alm Alktb, T1.

[6] 'bd Almqswd, Hsnyh Ghnymy. (2005). Drasat Wbhwth Fy 'lm Nfs Altfl. T1. Alqahrh. 'alm Alktb.

[7] Ahmd, Aml Mhmd Mhmd. (2000). " Astkhdam B'd Alwsa't Altknwlwjyh Wathrh 'la Aktsab Tfl Ma Qbl Almdrsh B'd Mfahym Alryadyat", Rsalt Majstyr Ghyr Mnshwrh. Jam't 'yn Shms. M'hd Aldrasat Al'lya Lltfwlh. Msr.

[8] Balfqyh, Njyb Mhfwz Abwbkr. (2000). " Edmaj Alhaswb Fy Almnhj: Atjahat M'lmat Ryad Alatfal Walmrhlh Altasysyh Fy Dw' B'd Almtghyrat" Www. Balfakih. Net

[9] Bdyr, Kryman Mhmd. (2001). "Alast'dad Llqra'h Ltfl Alrwdh Fy Dw' Astkhdam Alhaswb Walkhbrat Almbashrh (Alrhlat)", Mjlh Alqra'h Walm'rfh: Aljm'yh Almsryh Llqra'h Walm'rfh, Klyt Altrbyh. Jam't 'yn Shms. Al'dd1.

[10] Bhadr, S'dyh Mhmd. (2003). Bramj Trbyh Atfal Ma Qbl Almdrsh Alardn. T1. 'man. Dar Almsyrh. 
[11] Btaynh, Nwr. (2006). Astkhdam Alhaswb Alt'lymy Fy Ryad Alatfal. Alardn. 'man: 'alm Alktb Alhdyth

[12] Eyfal, 'ysa. (2004). Mdkhl Ela Alt'lym Fy Altfwlh Almbkrh. Ahmd Hsyn Alshaf'y, Rshd Fam Mnswr. T1. Al'yn, Dar Alktab Aljam'y.

[13] Aldrys, Mnahl 'bd Al'zyz. ( 2003 ). "Athr Astkhdam Brmjyat Alwsa't Almt'ddh 'la T'lm Almfahym Alryadyh Fy Ryad Alatfal Bmdynh Alryad". Rsalt Majstyr Ghyr Mnshwrh. Klyt Altrbyh. Jam't Almlk S'wd.

[14] Ebrahym, 'bdalltyf. (1990). Almnahj Assha Wtnzymatha Wtqwym Athrha. Alqahrh, Mktbt Msr, Alqahrh.

[15] Ebrahym, Fwzy Th W Alklzh, Rjb Ahmd. (1986). Almnahj Alm'asrh. T3. Mkh Almkrmh. Mktb Altalb Aljam'y.

[16] Hfnawy, Mhmwd Mhmd.(2014). " Fa'lyt Brnamj Elktrwny Leksab B'd Almfahym Alby'yh Lda Atfal Mrhlt Alryad Alm'aqyn Sm'yaan Balmmlkh Al'rbyh Als'wdyh". Mjlt Al'lwm Alensanyh Walajtma'yh: Jam't Alemam Mhmd Bn S'wd. Al'dd 32.

[17] Hmad, Khlyl 'bdalftah W Fwrh, Nahd Sbhy. (2004). " Dwr Altknwlwjya Fy Tnmyt Alast'dad Alqra'y Lda Ryad Alatfal Fy Mhafzat Ghzh " Alm'tmr Al'lmy Alrab' ( Alqra'h Wtnmyh Altfkyr), Alqahrh: Aljm'yh Almsryh Llqra'h Walm'rfh.

[18] Alhrahshh, Mhmd 'bwd. (2005). "Fa'lyt Albramj Altdrybyh Llm'lmyn Fy Mdyryat Altrbyh Walt'lym Fy Mhafzt Erbd Mn Wjht Nzr Almtdrbyn". Mjlt Alqra'h Walm'rfh: Aljm'yh Almsryh Llqra'h Walm'rfh. Klyt Altrbyh. Jam't 'yn Shms. Al'dd 42.

[19] Hwashyn, Mfyd Njyb Whwashyn Zydan Njyb. (2002). Ershad Altfl Wtwjyhh. T1. 'man. Alardn. Dar Alfkr.

[20] Alhwtyan, 'bdal'zyz .(1420h). "Atfalna Walhaswb".Mjlt Altdryb Waltqnyh: Al'dd Alsads.

[21] Abw Aljbyn, Hyfa' Ywsf. (2012). " F'alyt Brnamj Tdryby Lltfa'l M' Alrswmat Alfnyh (Alswr) Fy Tnmyh Aldka' Alanf'aly Lda 'ynh Mn Atfal Alrwdh Fy Alardn". Rsalt Dktwrah. Aljam'h Alardnyh. 'man. Alardn.

[22] Alkhryby, Halh Farwq Ahmd Wamyn, Eyman Zky Mhmd. (2005). Bna' Wtnfyd Alwhdat Aldrasyh Fy Ryad Alatfal. T1. Mkh Almkrmh. Almktbh Alfyslyh.

[23] Alkhthylh, Hnd Bnt Majd. ( 2000 ). Edart Ryad Alatfal. Al'yn, Dar Alktab Aljam'y.

[24] Alkhwly, Mhmd 'ly. (1994). Qamws Altrbyh. T3. Lbnan. Byrwt. Dar Al'lm Llmlayyn.

[25] Khwndnh, Ahlam 'Eadl. (1428h). "Fa'elyh Mnasht T'elymyh Mqtrhh Fy Thy'eh Alatfal Lt'elm Alqra'h Walktabh Fy Ryad Alatfal".Rsalh Majstyr Ghyr Mnshwrh. Klyt Altrbyh. Jam't Am Alqra.

[26] Mhmd, Jyhan Ltfy W Bsfr, Khdyjh 'bdallh. (2011). Trq Tdrys Ryad Alatfal Fy Dw' M'ayyr Aljwdh. Almmlkh Al'rbyh Als'wdyh. Alryad. Mktbt Alrshd.

[27] Sabr, Mlkh W Zamkh, Ghadh Ebrahym. (2003). "Athr Brnamj Alt'lm Fy Blad Alal'ab Fy Aktsab B'd Almfahym Latfal Alrwdh Fy Jdh". Mjlt Alqra'h Walm'rfh: Aljm'yh Almsryh Llqra'h Walm'rfh. Klyt Altrbyh. Jam't 'yn Shms. Al'dd23.

[28] Salh, Majdh Mhmwd Mhmd. (2000). Alhaswb Alt'lymy Wtrbyh Altfl. Aleskndryh. Almktb Al'lmy Llnshr Waltwzy'.

[29] Salh, Majdh Mhmwd Mhmd. (2002). Alhaswb Fy T'lym Alatfal. T1. Alardn. Dar Alfkr.

[30] Salh, Majdh Mhmwd Mhmd. (1997). "Fa'lyt Astkhdam Rkn Alhaswb Fy Tnmyh Almfahym Alryadyh Almrtbth Bal'laqat Altwbwlwjyh Lda Tfl Ma Qbl Almdrsh". Alm'tmr Al'lmy Altas'. Aljm'yh Almsryh Llmnahj Wtrq Altdrys. Klyt Ryad Alatfal. Aleskndryh. Ywlyw1997m

[31] Alshrbyny, Zkrya Wsadq Ysryh. (2011). "Nmw Almfahym Al'lmyh Llatfal" Brnamj Mqtrh Wtjarb Ltfl Ma Qbl Almdrsh. Alqahrh. Dar Alfkr Al'rby.

[32] Shrf, Eyman 'bdallh Mhmd. (2003). " Brnamj Mqtrh Ltnmyh Alast'dad Llqra'h Bastkhdam Alhaswb Latfal Alrwdh". Rsalt Majstyr Ghyr Mnshwrh. Jam't 'yn Shms. Alqahrh.

[33] Alshwy'r, Msha'l 'bdalrhmn 'bdallh. (1998). " Atjahat Almshrfat Walmdyrat Walm'lmat Fy Ryad Alatfal Bmdynh Alryad Nhw Edkhal Alhaswb Kwsylh T'lymyh". Rsalt Majstyr Ghyr Mnshwrh. Jam't Almlk S'wd. Alryad.

[34] Slyman, Slyman 'wad Waljmal, Ahmd. (2002). Aldlyl Alershady Ledkhal Wttwyr Altrbyh Altknwlwjyh Fy Alt'lym Al'am. T1. Mktb Alywnskw Aleqlymy Lltrbyh Fy Aldwl Al'rbyh. Byrwt.

[35] Alsmady, Halh Hmad - Mrwh, Njwa Mnla. (2006) . Dlyl Alm'lmh Lmnhj Alt'lm Aldaty Lryad Alatfal. T1. Alryad. Wzarh Altrbyh Walt'lym.

[36] Alsny'e, Blsm 'bdallh. (2003). "Atjahat Alm'elmat Nhw Edmaj Anshth Alhaswb Fy Mrhlh Ryad Alatfal". Bhth Majstyr Ghyr Mnshwr. Jam't Almlk 'bdal'zyz. Jdh, Klyt Alaqtsad Almnzly. Qsm Drasat Altfwlh.

[37] Syraj, Jwn W Maklywd, Eyan. (2005). "D'm Alt'lm Fy Snwat Altfwlh Almbkrh Fy Mjalat Al'lwm Waltsmymat Waltknwlwjya". Trjmt Hany Mhdy Aljml. Alqahrh. Mjmw't Alnyl Al'rbyh.

[38] Syraj, Jwn W Waytbryd, Dyfyd. (2006). "Tnmyt Mharat Tknwlwjya Alm'lwmat Walatsalat Fy Snwat Altfwlh Almbkrh "Trjmh Bha' Shahyn. Alqahrh. Mjmw't Alnyl Al'rbyh.

[39] Altrkyt, Swsn Ebrahym. (2003). Alatfal Wall'b. T1. Alkwyt. Mktbt Alflah.

[40] Altwbjy, Hsyn Hmdy. (1996). "Altrbyh Walhaswb R'yt Wwaq'". Alywnskw, Almnzmh Al'rbyh Lltrbyh Walthqafh Wal'lwm, Edarh Altqnyat Altrbwyh. 